\title{
Assessing the impact of uncertainty on flood risk estimates with reliability analysis using 1-D and 2-D hydraulic models
}

\author{
L. Altarejos-García ${ }^{1,2}$, M. L. Martínez-Chenoll ${ }^{1}$, I. Escuder-Bueno ${ }^{1}$, and A. Serrano-Lombillo ${ }^{2}$ \\ ${ }^{1}$ Instituto de Ingeniería del Agua y Medio Ambiente, UPV, ETSICCP, Edificio 4E - Camino de Vera s/n, \\ 46022 Valencia, Spain \\ ${ }^{2}$ iPresas Risk Analysis, Centro de Desarrollo Empresarial, UPV, Edificio 9B - Camino de Vera s/n, 46022 Valencia, Spain \\ Correspondence to: L. Altarejos-García (luis.ag@hma.upv.es, laltarejos@ipresas.com)
}

Received: 17 January 2012 - Published in Hydrol. Earth Syst. Sci. Discuss.: 24 January 2012

Revised: 1 June 2012 - Accepted: 6 June 2012 - Published: 5 July 2012

\begin{abstract}
This paper addresses the use of reliability techniques such as Rosenblueth's Point-Estimate Method (PEM) as a practical alternative to more precise Monte Carlo approaches to get estimates of the mean and variance of uncertain flood parameters water depth and velocity. These parameters define the flood severity, which is a concept used for decision-making in the context of flood risk assessment. The method proposed is particularly useful when the degree of complexity of the hydraulic models makes Monte Carlo inapplicable in terms of computing time, but when a measure of the variability of these parameters is still needed. The capacity of PEM, which is a special case of numerical quadrature based on orthogonal polynomials, to evaluate the first two moments of performance functions such as the water depth and velocity is demonstrated in the case of a single river reach using a 1-D HEC-RAS model. It is shown that in some cases, using a simple variable transformation, statistical distributions of both water depth and velocity approximate the lognormal. As this distribution is fully defined by its mean and variance, PEM can be used to define the full probability distribution function of these flood parameters and so allowing for probability estimations of flood severity. Then, an application of the method to the same river reach using a 2-D Shallow Water Equations (SWE) model is performed. Flood maps of mean and standard deviation of water depth and velocity are obtained, and uncertainty in the extension of flooded areas with different severity levels is assessed. It is recognized, though, that whenever application of Monte Carlo method is practically feasible, it is a preferred approach.
\end{abstract}

\section{Introduction}

Flooding poses a risk to people and causes significant economic costs. In the last century flood disasters accounted for $12 \%$ of all deaths from natural hazards (DEFRA, 2009). The number of flood disasters registered during the period 1990 1998 was more than those in the period 1950-1985, and the associated economic losses were seven times higher (Berz, 2000). During the period 2000 to 2006 water-related disasters killed more than 290000 people, affecting more than 1.5 billion, and inflicting more than US\$ 422 billion of damage (UNWWAP, 2009). Though the operation of flood disasters defence systems contribute to reduce risks, these cannot be completely eliminated and non-structural measures such as flood forecasting, warning, planning and others become even more significant on reducing flood disasters risk. For this reason, there is a requirement for methods to estimate flood disasters risk (societal and economical risk) and the effect of structural and non-structural measures on risk reduction (Escuder-Bueno et al., 2011). Flood disasters risk can be defined as the combination of the probability of a flood event, called hazard, with the potential adverse consequences for human health, the environment, cultural heritage and economic activity associated with a flood event (European Parliament, Directive 2007/60/EC), called vulnerability. Risk is commonly expressed by the notation

Risk $=$ Hazards $\times$ Vulnerability

Its units are the ones used for measuring the vulnerability divided per time, for instance a monetary unit or a number of victims per year, because the hazard probability has units 
of time $e^{-1}$. Flood disasters risks can be analyzed by calculating the probability of an event occurring and the subsequent impact that it has on a receptor.

Hazard in risk models can be expressed as

Hazard $=$ Load Probability $\times$ System Response.

The Load corresponds to the hydrological input, usually identified by a flow discharge. The Load Probability has units of time ${ }^{-1}$. The System Response, when uncertainties are incorporated into the models, is a conditional probability and has no units. The System Response is usually expressed in terms of velocity, $v$, water depth, $y$, and extension of the flooded area, $A_{\mathrm{f}}$. These parameters are outputs of the flood model and can be considered as performance functions of the system. Vulnerability in terms of loss of lives includes the computation of population at risk and fatality rates. The fatality rates can be calculated as a function of flood severity and warning time. Vulnerability in terms of economic losses is obtained by identifying homogeneous areas, value of assets, defining reference costs, estimating percentages of damage based on water depth in each area and flood scenario, etc.

Therefore, risk can be defined mathematically as

Risk $=$ Load Probability $\times$ System Response $\times$ Vulnerability.

The state of the art of this kind of analysis is a collection of raster maps of flood extent for several annual exceedance probabilities, including information on water depth and velocity. This maps are combined with a structure inventory of the flooded area that comprises structure type (residential, commercial, industrial, etc.), structure location and value, occupancy type and associated depth-percent damage functions, among other categories, that help to define the Vulnerability (USACE, 2008; Escuder-Bueno et al., 2011). Parameters commonly used to measure the severity of a flood are water depth, velocity, together with the dragging parameter, $v \cdot y$, and the sliding parameter, $v^{2} \cdot y$. Due to the uncertainties that exist at several levels of the process these parameters are performance functions of basic random variables, being random variables themselves.

As it has been mentioned, the hydrological input, defined in terms of a flood hydrograph, affects the Load Probability term of the equation of Risk. Flood hydrographs are influenced by many random factors, such as rainfall pattern and amount, watershed geomorphology, ground infiltration rate, vegetation of the watershed and temperature, etc. Uncertainty on flood hydrographs has been addressed by several authors (Sarino and Serrano, 1990; Yue et al., 2002). The second term of the Risk equation is the System Response. This response is controlled by the quality of topography information, friction coefficient and type of model used: 1-D, 2-D or coupled 1-D-2-D models. Uncertainty can be taken into account by setting the model in a probabilistic framework, i.e. combining the model and a probabilistic description of the input parameters. The uncertainties are represented by random variables, therefore the response is also a random variable obtained by the propagation of the random input through the model. Uncertainty in topography for numerical flood modelling can be reduced thanks to remote sensing techniques such as laser altimetry (Cobby et al., 2001; Gregory at al., 2007; Sanders, 2007; Cook and Merwade, 2009; Shatnawu and Goodall, 2010) which allow obtaining floodplain digital elevation models, DEMs, with a high degree of accuracy. The specification of flow resistance is also subjected to uncertainty, with different existing laws and methods (Wohl, 1998; Pappenberger et al., 2005) and a wide spectrum of values to be selected. Factors influencing the friction coefficient include bed material, bed forms both at micro- and mesoscale, and the presence of vegetation in the channel and in the floodplains (Horrit, 2006). The spatial and temporal variability of these parameters adds difficulty in the assessment of the friction coefficient (Mason et al., 2003). This is the main source of uncertainty considered in this paper.

Regarding analysis models, 1-D models, despite their limitations, are commonly used in engineering practice as they are simple and allow fast calculations of flood parameters (Yoshida and Dittrich, 2002; Helmio, 2005). These models cannot accurately represent flood plain flows so 2-D models where the velocity vector has two components have been developed and are now common tools in flood modelling (Horrit and Bates, 2002; He et al., 2008; Wright et al., 2008; Remo et al., 2009). 2-D models are solved by numerical methods and their computation even for single set of parameters can be time demanding, depending on the extent of the area and the calculation mesh density, i.e. number of points where inundation parameters are going to be calculated per unit area (Bladé et al., 1994; USACE, 2002). To combine the advantages and capabilities of both approaches some coupled 1-D-2-D models have been developed (Kun-Yeun Han et al., 1998; Latorre at al., 2009; Kuiry et al., 2010; Finaud-Guyot et al., 2011).

A common approach to solve problems where parameter uncertainty is present is the Monte Carlo Method (Aronica et al., 1998; Romanowicz and Beven, 1998). Variability of the performance functions that describe the system response is captured doing multiple realisations of the model using different sets of values of the basic random variables. These sets of values are generated according to the probability distributions of the random variables and their possible correlations (Rubinstein, 1981). The method allows considering random variables with different probability distributions and non linear performance functions. In order to get a sound approximation of the performance functions in terms of the form of their probability distributions and accuracy in the estimation of the parameters that define the distributions it is necessary to perform a large number of simulations, assuring a dense mapping of the probability functions of the basic random variables. This is the major drawback of the method, as when there is a large number of random variables and/or the model is complex, computing time can be so high that 
the method becomes simply inapplicable for practical purposes. To avoid this problem it is possible to use simplified models that are much less demanding in terms of computing time. An example of this is the 1-D well known HECRAS model, that can be used in a probabilistic framework due to its relatively short calculation time (Pappenberger et al., 2005). Another approach if 2-D models have to be used is the search of an approximation of the 2-D model which can be evaluated for fast explorations of its probabilistic behaviour by techniques such as spectral approximations (Liu et al., 2010). This latter approach is still in the research field and hardly used by engineers in everyday practice. Some 1-D and 2-D models available to engineers include MIKE 11 and MIKE 21 (DHI, 2011), BASEMENT (ETH Zurich, 2011), ISIS 2-D (Halcrow, 2011), Infoworks 2-D (Innovize, 2011), LISFLOOD (Van der Knijff et al., 2010), SOBEK (Deltares, 2011), GISPLANA (Estrela and Quintas, 1996) and IBER (CEDEX, 2010).

The objective pursued in this paper is to demonstrate how practical estimates of the variability of uncertain flood parameters can be obtained with a reasonable balance between accuracy and effort. This paper addresses the use of reliability techniques such as Rosenblueth's Point-Estimate Method, PEM, as a practical alternative to more precise Monte Carlo approaches to get estimates of the mean and variance of flood parameters such as water depth and velocity. These parameters define the flood severity, which is a concept used for decision-making in the context of flood disaster risk assessment. The method proposed is particularly useful when the degree of complexity of the hydraulic models makes Monte Carlo inapplicable in terms of computing time, but when still an approximate measure of the variability of these parameters can be of help for decision making.

In Sect. 2 the fundamentals of the point-estimate method are shown. In Sect. 3 a case study is presented and three models of analysis are described. The first is a simple 1-D prismatic channel model, with uniform steady flow. This model is used to explore the transfer of variability between input random variables such as the friction coefficient and performance functions like water depth and velocity. The second model is a 1-D non prismatic channel model. This is a steady flow model of the whole river reach implemented in HEC-RAS. We have chosen this code as it is one of the most frequently used codes for 1-D steady flow analysis. The third model is a 2-D structured grid model. This model is a Shallow Water Equations, SWE, 2-D unsteady flow model, implemented in the commercial code GUAD-2-D (InclamUniversity of Zaragoza, 2008). This code was chosen because it has been used by the authors on previous research and professional applications and it is also frequently used by engineers in our environment (Olivera et al., 2008; Gracia et al., 2010; Vallés-Morán et al., 2012). In Sect. 4 pointestimate method and Monte Carlo techniques are used in combination with 1-D models to estimate the statistical properties of the performance functions and results are compared.
In Sect. 5 point-estimate method is used in combination with the 2-D SWE model to get estimates of flood severity in terms of mean and standard values of water depth, velocity and dragging coefficient. Section 6 gives some conclusion remarks.

It should be noted that the test models are not calibrated. In this sense, the paper compares results between different methods to deal with uncertainty using the same mathematical hydraulic models.

\section{Estimation of uncertainty}

\subsection{Sources of uncertainty and existing methods}

In engineering problems physical and probabilistic models are used as mathematical idealizations of reality. Formulation of reliability, risk and decision problems involves a set of input random variables, $X$, parameterized sub-models describing their statistical distributions and physical sub-models that describe the relationships between the random variables and the derived quantities, $Y$. In this context, the sources of uncertainty include (Der Kiureghian and Ditlevsen, 2007): inherent uncertainty in the random variables $X$; uncertain model error resulting from the selection of the form of the probabilistic sub-model; uncertain model error resulting from the selection of the physical sub-models; statistical uncertainty in the estimation of the parameters of the probabilistic sub-model; statistical uncertainty in the estimation of the parameters of the physical sub-model; uncertain errors involved in measuring of observations; and uncertainty derived from computational errors, numerical approximations or truncations, when computation procedures employs iterative calculations that involve convergence tolerances and truncation errors.

To deal with at least part of the aforementioned sources of uncertainty several methods can be used (Shresta and Solomatine, 2008), including analytical methods, approximation methods, simulation and sampling methods, Bayesian methods such as the generalized likelihood uncertainty estimation method or GLUE (Beven and Binley, 1992), statistical methods based on the analysis of model errors (Kelly and Krzysztofowicz, 1997) and methods based on fuzzy set theory (Pappenberger et al., 2007).

The approximation methods provide only the moments of the distribution of the derived parameters. Due to their simplicity and low computational demand these methods are suited for practical applications in hydrology and water resources by engineers not familiar with more complex techniques. The point-estimate method belongs to this group.

\subsection{The point-estimate method}

In this Section the fundamentals of Rosenblueth's pointestimate method for approximating low-order moments of functions of random variables is presented (Rosenblueth, 
1981). The mathematical problem is that of a random variable or variables, $X$, with probability distribution function defined by the probability density function (PDF), $f_{X}(x)$, and another variable, $Y$, which is a deterministic performance function of $X, Y=g(X)$. The random variables are, in this paper, the three bed friction coefficients defined by Manning's roughness, $n_{i}(i=1,2,3)$, for the main channel and both overbanks. The performance function $Y$ is the water depth and also the velocity, taking into account that these two variables are fully correlated. It is assumed that $Y$ has a PDF defined by $f_{Y}(y)$. The problem that point-estimate faces is how to approximate the low-order moments of $f_{Y}(y)$ using only the low-order moments of $f_{X}(x)$ and the function $g(X)$.

The point-estimate method determines the first two moments of the performance function $g(X)$ replacing the continuous random variables $X$ by discrete random variables whose probability mass function, $\mathrm{PMF}, p_{X}(x)$, has the same moments of order $k$ as does $f_{X}(x)$. The PMF $p_{X}(x)$ is transformed using $g(X)$ to obtain another discrete function with a PMF denoted $p_{Y}(y)$. This latter PMF is used to calculate the moments which are assumed to approximate the moments of $Y$ in the continuous case.

The first moment of $f_{X}(x)$ about the origin is the mean, $\mu_{X}$

$\mu_{X}=\int x \cdot f_{X}(x) \cdot \mathrm{d} x$.

The higher-order central moments of $f_{X}(x)$ of order $k$ are

$\mu_{X k}=\int\left(x-\mu_{X}\right)^{k} \cdot f_{X}(x) \cdot \mathrm{d} x$.

The second central moment, $\mu_{X 2}$, is the variance, and its square root is the standard deviation, $\sigma_{X}$. The corresponding moments of order $k$ the discrete $\operatorname{PMF} p_{X}(x)$ are

$\mu_{X k}=\sum\left(x-\mu_{X}\right)^{k} \cdot p_{X}(x)$.

Equating the moments of $f_{X}(x)$ and $p_{X}(x)$ yields

$\int\left(x-\mu_{X}\right)^{k} \cdot f_{X}(x) \cdot \mathrm{d} x=\sum\left(x-\mu_{X}\right)^{k} \cdot p_{X}(x)$.

An approximation to integration is done using numerical quadrature procedures. The selection of the optimal values of the coordinates at which evaluate the integrand and the corresponding weights is treated with Gaussian quadrature procedures. So it can be seen from Eq. (7) that Rosenblueth's method is an application of Gaussian quadrature procedures (Christian and Baecher, 1999). This discretization is made in a few points for each random variable (two or three points), where mass probability is concentrated in such a fashion that the sum of the probabilities assigned to each point is 1 for each random variable (Harr, 1987). The two-point method concentrates the mass probability of the random variable $X_{i}$ in two points, $x_{i+}$ and $x_{i-}$, each of them with a mass probability of $P_{i+}$ and $P_{i-}$. Points are centred about the mean value, $\mu_{X i}$, at a distance of $d_{i+}$ and $d_{i-}$ times the standard deviation $\sigma_{X i}$, respectively.

$P_{i+}+P_{i-}=1$
$x_{i+}=\mu_{X_{i}}+d_{i+} \cdot \sigma_{X_{i}}$
$x_{i-}=\mu_{X_{i}}-d_{i-} \cdot \sigma_{X_{i}}$.

Coefficients $d_{i+}$ and $d_{i-}$ are determined using the skew coefficient, $\gamma_{i}$, of the random variable $X_{i}$ :

$d_{i+}=\frac{\gamma_{i}}{2}+\sqrt{1+\left(\frac{\gamma_{i}}{2}\right)^{2}}$

$d_{i-}=d_{i+}-\gamma_{i}$.

Probabilities are assigned to each point according to

$\begin{aligned} P_{i+} & =\frac{d_{i-}}{d_{i+}+d_{i-}} \\ P_{i-} & =1-P_{i+}\end{aligned}$

A number of $2^{m}$ values of discrete probabilities should be obtained by combination of the point probabilities of each of the $m$ random variables with the other random variable's probabilities. These probabilities are $P_{(\delta 1, \delta 2, \ldots, \delta m)}$, where $\delta_{i}$ is the sign $( \pm)$. Their values are calculated as

$P_{(\delta 1, \delta 2, \ldots, \delta m)}=\prod_{i=1}^{m} P_{i, \delta i}+\sum_{i=1}^{m-1}\left(\sum_{j=i+1}^{m} \delta_{i} \delta_{j} a_{i j}\right)$

where the coefficients $a_{i j}$ are calculated as

$a_{i j}=\frac{\frac{\rho_{i j}}{2^{m}}}{\sqrt{\prod_{i=1}^{n}\left(1+\left(\frac{\gamma_{i}}{2}\right)^{2}\right)}}$.

Being $\rho_{i j}$ the correlation coefficient between random variables $X_{i}$ and $X_{j}$.

The performance function $g(X)$ has to be evaluated $2^{m}$ times, corresponding to the $2^{m}$ possible combinations of discrete probability points $P\left(\delta_{1}, \delta_{2}, \ldots, \delta_{m}\right)$, obtaining $Y\left(\delta_{1}\right.$, $\left.\delta_{2}, \ldots, \delta_{m}\right)=g^{*}\left(\delta_{1}, \delta_{2}, \ldots, \delta_{m}\right)$. Once this is accomplished, the expected value of the $k$-th power of the probability distribution of $Y$ is determined by:

$E\left[Y^{k}\right] \approx \sum P_{(\delta 1, \delta 2, \ldots, \delta m)} Y_{(\delta 1, \delta 2, \ldots, \delta m)}^{k}$.

So for $k=1$ what we have is the first moment about the origin, which is the mean, $\mu_{Y}$

$E[Y] \approx \sum P_{(\delta 1, \delta 2, \ldots, \delta m)} Y_{(\delta 1, \delta 2, \ldots, \delta m)}$.

And for $k=2$ the second moment about the origin is obtained

$E\left[Y^{2}\right] \approx \sum P_{(\delta 1, \delta 2, \ldots, \delta m)} Y_{(\delta 1, \delta 2, \ldots, \delta m)}^{2}$. 
The variance of $Y$ can be calculated from the first two moments about the origin as:

$\sigma_{Y}^{2}=\mu_{Y 2}=E\left[\left(Y-\mu_{Y}\right)^{2}\right]=E\left[Y^{2}\right]-\mu_{Y}^{2}$.

So it is possible to determine the mean and the variance of the random variable $Y$, but the shape of the distribution remains unknown.

The method allows to handle random variables $X$ with different symmetrical distributions. The method loses precision as nonlinearity of $g(X)$ increases and if moments over the second are to be obtained (Harr, 1987). It does not provide a measure of the contribution of each random variable to the overall variance, so it is not an adequate method to filter the most relevant random variables. A disadvantage of the method is that the performance function has to be evaluated $2^{m}$ times, being $m$ the number of random variables. If $m$ is large, the method requires a considerable computational effort, above all if $g(X)$ evaluation is not straightforward, as it is the case with 2-D SWE models.

The method performs reasonably well when $g(X)$ can be approximated by a third-order or less polynomial and when the coefficient of variation of $X, \mathrm{COV}$, defined as the ratio between standard deviation and mean value, is not large (Christian and Baecher, 1999).

\section{Case study}

In this Section the river reach and the different hydraulic models used for the study are described.

\subsection{Model of the Turia river reach}

The modelled stream is a reach of the Turia river (Fig. 1a), located several kilometers upstream of the city of Valencia, in the eastern part of Spain. The domain modelled has a length of $1 \mathrm{~km}$ and an average slope of $2.3 \mathrm{~m} \mathrm{~km}^{-1}$. The DEM of the terrain has a mesh size of $1 \times 1 \mathrm{~m}$.

The bed friction coefficient used is the Manning's $n$. Three zones are defined with different bed friction values: the main channel, $n_{\mathrm{ch}}$, the left overbank, $n_{\text {lob }}$, and the right overbank, $n_{\text {rob }}$ (see Fig. 1b). The $n$ values over each of the three domains are subjected to uncertainty and therefore are defined as random variables in the model. The variables are assumed to be uncorrelated in this paper, although it is recognized that in fact some correlation may exist between the bed friction values in the defined areas. Nevertheless the methodology exposed in this paper can be applied without difficulty to correlated random variables. No spatial variability is considered inside the three defined zones, which corresponds well with the low degree of spatial heterogeneity observed in the reach analyzed.

Different probability distributions have been used by different authors to statistically characterise the friction coefficient, such as the normal (Cesare, 1991; Mays and Tung,
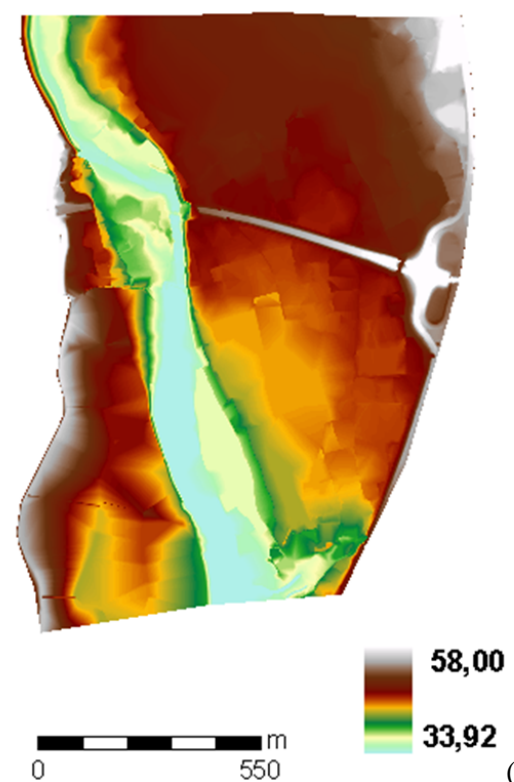

(a)

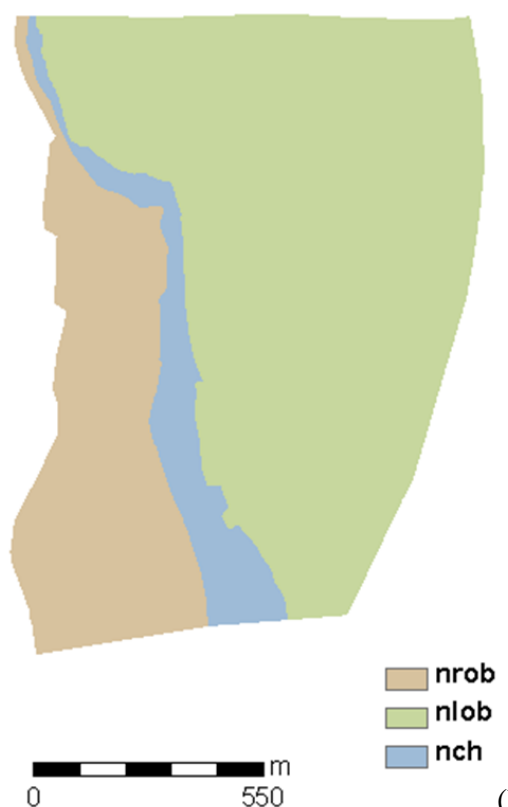

(b)

Fig. 1. Digital Elevation Model of the study river reach (a) and zones considered for different bed friction values (b).

1992; Horrit, 2006), triangular (Yeh and Tung, 1993), lognormal (USACE, 1986; Liu and Matthies, 2010) and uniform distributions (Johnson, 1996; Pappenberger et al., 2005). In this paper the uniform distribution is selected to examine how point-estimate method performs when distributions have such a high variability. To check the impact of the type of probability distribution of the bed friction on water depth and velocity estimates, also triangular symmetrical and normal distributions have been tested with the 1-D uniform flow model. In the case of the triangular symmetrical distribution the minimum and maximum values are the same as those of 
Table 1. Probability Distribution Functions (PDF) for bed friction coefficient, $n$.

\begin{tabular}{llccccc}
\hline PDF & & $\begin{array}{c}\text { Mean } \\
\mu\end{array}$ & $\begin{array}{c}\text { SD } \\
\sigma\end{array}$ & $\begin{array}{c}\text { COV } \\
=\sigma / \mu\end{array}$ & $\begin{array}{c}\text { Min. } \\
\text { value }\end{array}$ & $\begin{array}{c}\text { Max. } \\
\text { value }\end{array}$ \\
\hline \multirow{2}{*}{ Uniform } & $n_{\text {lob }}$ & 0.065 & 0.020 & 0.308 & 0.030 & 0.100 \\
& $n_{\text {ch }}$ & 0.045 & 0.014 & 0.311 & 0.020 & 0.070 \\
& $n_{\text {rob }}$ & 0.085 & 0.032 & 0.376 & 0.030 & 0.140 \\
Triangular & $n_{\text {lob }}$ & 0.065 & 0.014 & 0.215 & 0.030 & 0.100 \\
& $n_{\text {ch }}$ & 0.045 & 0.010 & 0.222 & 0.020 & 0.070 \\
& $n_{\text {rob }}$ & 0.085 & 0.022 & 0.259 & 0.030 & 0.140 \\
& $n_{\text {lob }}$ & 0.065 & 0.020 & 0.308 & 0.025 & 0.105 \\
& $n_{\text {ch }}$ & 0.045 & 0.014 & 0.311 & 0.017 & 0.073 \\
& $n_{\text {rob }}$ & 0.085 & 0.032 & 0.376 & 0.021 & 0.149 \\
\hline
\end{tabular}

the uniform distribution. In the case of the normal distribution a different truncation has been adopted so the variable is confined exactly between the range $\left[\mu_{n}-2 \sigma_{n}, \mu_{n}+2 \sigma_{n}\right]$, with $\mu_{n}$ and $\sigma_{n}$ the mean and standard deviation of $n$. The probability distributions adopted for $n$ are summarized in Table 1 . The study has been undertaken with three different imposed flows at the upstream end of 200,300 and $500 \mathrm{~m}^{3} \mathrm{~s}^{-1}$.

\subsection{Numerical flood models}

In this Sub-section the three hydraulic models used in the study are described.

\subsubsection{Uniform flow model}

The first model used is a uniform flow model that is applied to a simplified 1-D prismatic channel geometry (Fig. 2a) of the river station RS 768 of the 1-D HEC-RAS model that is described in Sect. 3.2.2. The model assumes an infinite reach length with constant geometry in terms of cross section and slope. The slope of this ideal reach is $2.1 \mathrm{~m} \mathrm{~km}^{-1}$. This model has been prepared to explore the transfer of variability from bed friction coefficient to water depth and velocity functions under ideal conditions, without non-linear perturbations of flow due to changes in geometry. The implicit equation to be solved is the well-known uniform flow formula

$Q \cdot S^{-0.5}=\sum_{i} n_{i}^{-1} A_{i}(y)\left[R_{i}(y)\right]^{0.67}$

where $Q$ is the flow $\left(\mathrm{m}^{3} \mathrm{~s}^{-1}\right), S$ is the slope of the channel $\left(\mathrm{m} \mathrm{m}^{-1}\right), n_{i}$ is the random roughness coefficient in the $i$-th zone in which the section is divided, $A_{i}$ is the flow area of the $i$-zone $\left(\mathrm{m}^{2}\right), R_{i}$ is the hydraulic radius $(\mathrm{m})$ of the $i$-th zone and $y$ is the water depth $(\mathrm{m})$. In this case three zones have been defined $(i=3)$ : main channel and the left and right overbanks. The simplification of the geometry allows using algebraic expressions for $A_{i}(y)$ and $R_{i}(y)$. The model is implemented in a spreadsheet.

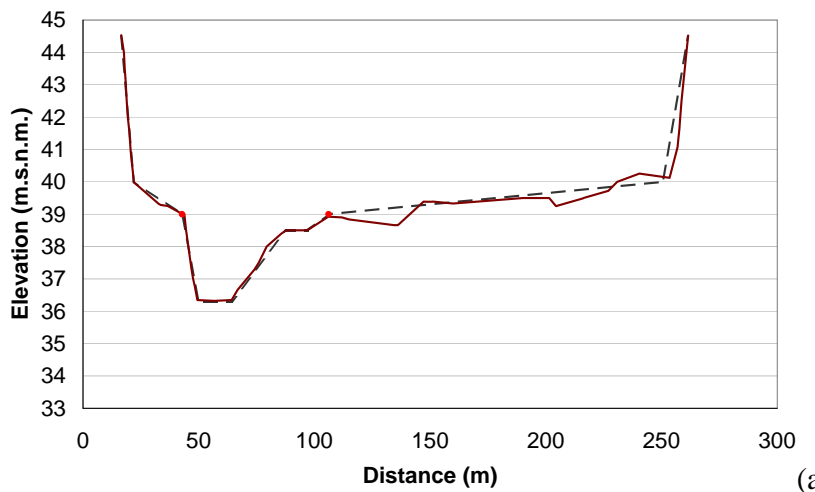

(a)

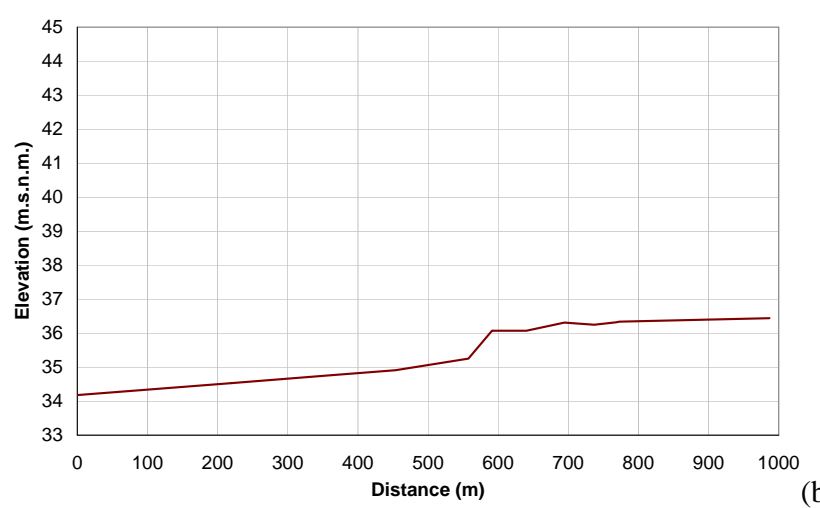

Fig. 2. 1-D model Geometry of the cross section at RS 768 of the HEC RAS model, with the simplified cross section for the uniform flow model showed with dashed line (a) and river reach ground profile for 1-D HEC-RAS model (b).

\subsubsection{1-D HEC-RAS model}

A 1-D non prismatic channel, gradually varied steady flow model of the reach has been prepared and implemented in HEC-RAS. This model is defined by 12 cross sections located along the reach and numbered according to their position in terms of distance in meters to the downstream end ( 0 ; 219; 353; 454; 558; 591; 640; 694; 737; 768; 773 and 987). Position of the bank stations that define the main channel and the overbanks is consistent with the extent of the zones defined in Fig. 2b. At the downstream boundary a normal depth condition is imposed assuming a friction slope of $1.9 \mathrm{~m} \mathrm{~km}^{-1}$ according to the average river slope further downstream. No upstream boundary condition is imposed in HEC-RAS as subcritical flow is assumed. This assumption is checked after the calculations. In this model the geometry varies between cross sections. The real cross section at RS 768 compared to the simplified section and the ground profile of the model can be seen in Fig. 2. 
Table 2. Uniform flow model. Adaptation of PDFs to water depth with uniform distributions for $n_{i}$ (1000 simulations).

\begin{tabular}{|c|c|c|c|c|c|c|c|}
\hline $\begin{array}{l}\text { Flow } \\
\left(\mathrm{m}^{3} \mathrm{~s}^{-1}\right)\end{array}$ & $\begin{array}{l}\text { Mean } \\
\mu(\mathrm{m})\end{array}$ & $\begin{array}{c}\mathrm{SD} \\
\sigma(\mathrm{m})\end{array}$ & $\begin{array}{l}\mathrm{COV} \\
=\sigma / \mu\end{array}$ & $\begin{array}{l}\text { Min. value } \\
\text { (m) }\end{array}$ & $\begin{array}{l}\text { Max. value } \\
\text { (m) }\end{array}$ & PDF & $\chi^{2}$ \\
\hline 200 & 3.23 & 0.3855 & 0.12 & 2.35 & 3.78 & $\begin{array}{l}\text { Beta Gen. } \\
\text { Triang. } \\
\text { Normal }\end{array}$ & $\begin{array}{l}104.9 \\
153.3 \\
359.2\end{array}$ \\
\hline 300 & 3.67 & 0.3856 & 0.11 & 2.83 & 4.28 & $\begin{array}{l}\text { Beta Gen. } \\
\text { Triang. } \\
\text { Normal }\end{array}$ & $\begin{array}{l}95.79 \\
174.6 \\
287\end{array}$ \\
\hline 500 & 4.27 & 0.4071 & 0.10 & 3.39 & 5.03 & $\begin{array}{l}\text { Beta Gen. } \\
\text { Triang. } \\
\text { Normal }\end{array}$ & $\begin{array}{l}103.9 \\
179 \\
184.1\end{array}$ \\
\hline
\end{tabular}

\subsubsection{2-D Shallow Water Equations model}

A 2-D Shallow Water Equations (SWE) flow model has been used to evaluate the system response in terms of water depth and velocities in the domain under analysis. The model solves the well-known 2-D finite volume shallow water equations

$$
\begin{gathered}
\frac{\partial h}{\partial t}+\frac{\partial(h u)}{\partial x}+\frac{\partial(h v)}{\partial y}=0 \\
\frac{\partial(h u)}{\partial t}+\frac{\partial\left(h u^{2}\right)}{\partial x}+\frac{\partial(h u v)}{\partial y}=-g h \frac{\partial(h+z)}{\partial x}+\frac{n^{2} u\left(u^{2}+v^{2}\right)^{0.5}}{h^{4 / 3}} \\
\frac{\partial(h v)}{\partial t}+\frac{\partial(h u v)}{\partial x}+\frac{\partial\left(h v^{2}\right)}{\partial y}=-g h \frac{\partial(h+z)}{\partial y}+\frac{n^{2} v\left(u^{2}+v^{2}\right)^{0.5}}{h^{4 / 3}}
\end{gathered}
$$

where $h$ is the flow depth, $u$ and $v$ the components of the depth averaged flow velocity vector, $z$ the bed elevation, $g$ the acceleration due to gravity and $n$ the Manning's coefficient of roughness. This model is a 2-D structured grid implemented in the commercial code GUAD 2-D (Inclam and University of Zaragoza, 2008; Murillo et al., 2008). The upstream boundary condition is an imposed inflow. For the downstream boundary condition the GUAD 2-D allows five different downstream conditions: (1) imposed hydrograph, (2) water level as function of time, (3) stage discharge relation, (4) critical flow and (5) flow over a spillway. Of these, the downstream boundary condition chosen is a stage-discharge relation, which has been obtained previously with the 1-D model, thus minimizing the differences between models. The continuous fields $h, u$ and $v$ are discretized over a structured mesh of elements that in this case are squares, but that can have other shapes such as triangles. The model is implemented over the DEM with a grid of 1140 rows and 1541 columns, rendering 1756740 cells of $1 \times 1 \mathrm{~m}$. The governing equations are integrated over each element. The finite volume method combines the main advantages of finite element methods, such as its great geometrical flexibility, with the main advantages of finite difference methods, such as its flexibility in the definition of discrete flow variables.
The finite volume method has some disadvantages in the representation of high order derivatives, so they should be used when the viscosity terms can be ignored. The problem is solved over time in GUAD 2-D using the Roe approximation based on the local linearization of each Riemann problem between adjacent cells. In the numerical model the source terms are projected on the basis of the eigenvectors and they are added to the discretization. The time step should be small enough to assure stability. A Courant-Friedrich-Levy condition of 0.8 is assumed in the code by default (Murillo et al., 2007).

\section{Application of the method}

In this Section the point-estimate method is used to calculate flood parameters. Results obtained using PEM in combination with uniform flow and 1-D HEC-RAS steady flow models are compared with those obtained with the same models but using the Monte Carlo approach.

\subsection{Uniform flow model - Monte Carlo solutions}

The first model used has been the uniform flow model described in previous Section. The number of random variables is three which correspond to Manning's $n$ values in main channel and both overbanks. Three flow values are considered, 200, 300 and $500 \mathrm{~m}^{3} \mathrm{~s}^{-1}$. Three different probability distributions have been used for $n_{i}$ according to Table 1, uniform, triangular and normal. The problem has been solved initially with Monte Carlo simulation with 1000 model runs. From these simulations the mean and standard deviation of water depth and velocity at the section have been estimated, and an adaptation of several probability distributions has been attempted, using the statistical tool @RISK (Palisade Corporation, 2005).

The results for water depth are shown in Tables 2 to 4 . In a first step the probability distributions to be fitted have been filtered so only those with lower and upper bounds have been considered, as distributions of $n_{i}$ are bounded as well. 

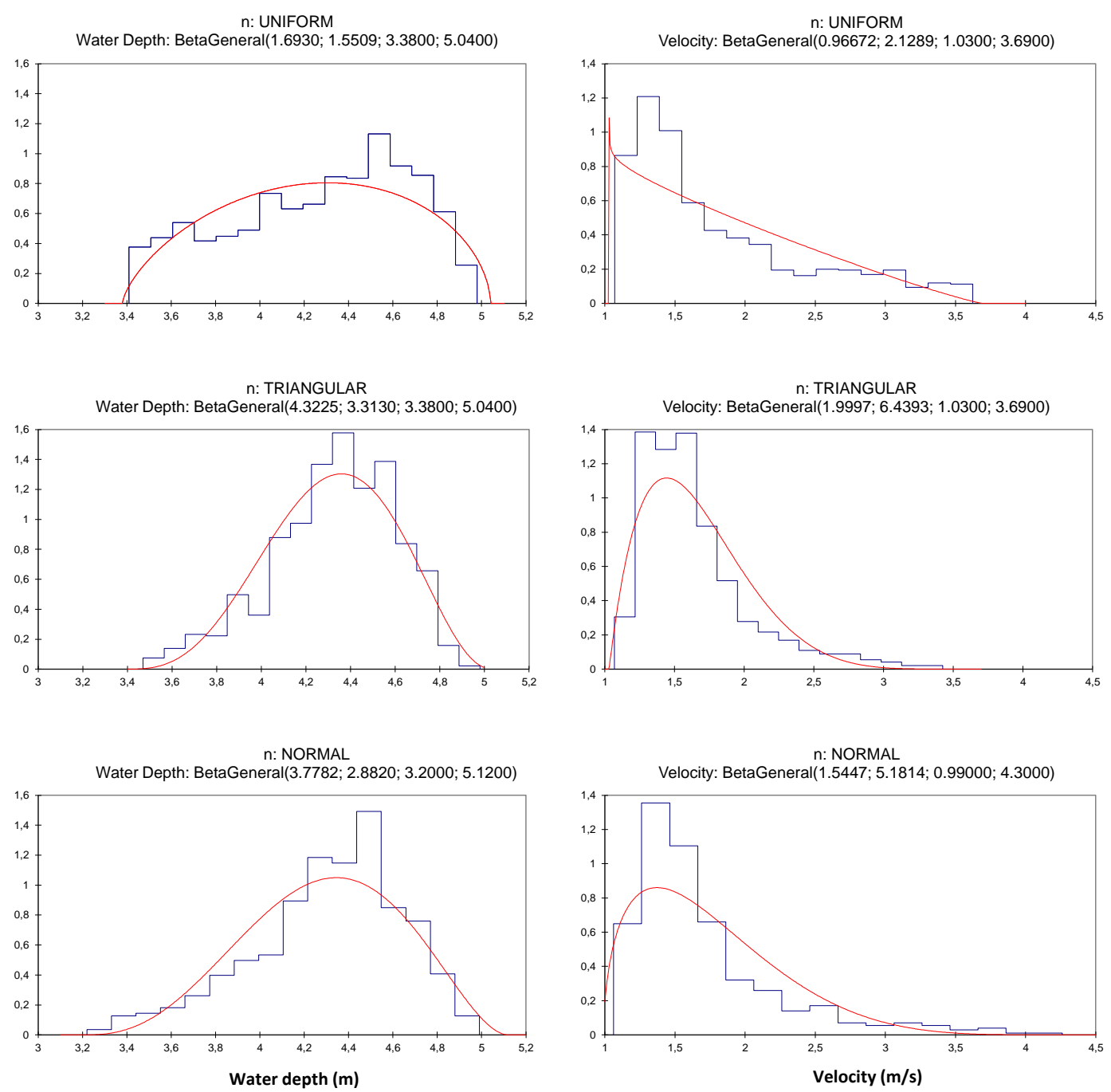

Fig. 3. Uniform flow model. Case flow $500 \mathrm{~m}^{3} \mathrm{~s}^{-1}$. Adaptation of 4-parameter beta PDF to water depth (left panels) and velocity values (right panels) obtained with Monte Carlo (1000 simulations), and for different distributions of $n_{i}$ : uniform (top panels), triangular (middle panels) and normal (bottom panels).

The distributions that best fit the data according to the $\chi^{2}$ test are the 4-parameter beta distribution (Beta General) and the 3-parameter triangular distribution. In a second step and for comparison purposes the normal distribution has been selected for fitting. The comparison of the 4-parameter beta distributions that best fit water depth for case flow $500 \mathrm{~m}^{3} \mathrm{~s}^{-1}$ when $n_{i}$ has different probability distributions is shown in Fig. 3. Graphical comparison of probability density functions suggest that better fitting is obtained when $n_{i}$ are triangular or normal distributed. The best approximation according to $\chi^{2}$ test is obtained when $n_{i}$ have triangular distributions. From Fig. 3 it can be seen that the probability distribution of the water depth is not symmetrical, showing some negative skewness. This indicates that symmetrical distributions such as the normal are not a good choice when attempting to describe water depth in a probabilistic way.
A similar analysis has been performed for velocity of flow. The procedure followed has been the same as for water depth. The bounded distributions that best fit the data according to the $\chi^{2}$ test are the 4-parameter beta distribution (Beta General) and the triangular distribution. Again, the normal distribution has been selected for comparison purposes. The results for velocity are shown in Tables 5 to 7 . The high values of the $\chi^{2}$ statistic indicates poor fitting in all cases. The comparison of the 4-parameter beta distributions that best fit velocities for flow case $500 \mathrm{~m}^{3} \mathrm{~s}^{-1}$ when $n_{i}$ has different probability distributions is shown in Fig. 3. The graphic comparison confirms the bad fitting seen in the $\chi^{2}$ goodness of fit test. It can be seen that the probability distribution of the velocity is strongly asymmetrical, showing positive skewness. The values of the $\chi^{2}$ statistic for a significance levels of $\alpha=0.05$ and $\alpha=0.01$ are shown in Table 8 . It can be seen that none of 
Table 3. Uniform flow model. Adaptation of PDFs to water depth with triangular distributions for $n_{i}$ (1000 simulations).

\begin{tabular}{|c|c|c|c|c|c|c|c|}
\hline $\begin{array}{l}\text { Flow } \\
\left(\mathrm{m}^{3} \mathrm{~s}^{-1}\right)\end{array}$ & $\begin{array}{l}\text { Mean } \\
\mu(\mathrm{m})\end{array}$ & $\begin{array}{c}\mathrm{SD} \\
\sigma(\mathrm{m})\end{array}$ & $\begin{array}{l}\text { COV } \\
=\sigma / \mu\end{array}$ & $\begin{array}{l}\text { Min. value } \\
\text { (m) }\end{array}$ & $\begin{array}{l}\text { Max. value } \\
\text { (m) }\end{array}$ & PDF & $\chi^{2}$ \\
\hline 200 & 3.25 & 0.2592 & 0.08 & 2.35 & 3.78 & $\begin{array}{l}\text { Beta Gen. } \\
\text { Triang. } \\
\text { Normal }\end{array}$ & $\begin{array}{l}120.2 \\
139.1 \\
145.5\end{array}$ \\
\hline 300 & 3.71 & 0.2709 & 0.07 & 2.83 & 4.28 & $\begin{array}{l}\text { Beta Gen. } \\
\text { Triang. } \\
\text { Normal }\end{array}$ & $\begin{array}{r}66.39 \\
74.1 \\
118.3\end{array}$ \\
\hline 500 & 4.33 & 0.2791 & 0.06 & 3.39 & 5.03 & $\begin{array}{l}\text { Beta Gen. } \\
\text { Triang. } \\
\text { Normal }\end{array}$ & $\begin{array}{l}80.77 \\
164.9 \\
133.6\end{array}$ \\
\hline
\end{tabular}

Table 4. Uniform flow model. Adaptation of PDFs to water depth with normal distributions for $n_{i}$ (1000 simulations).

\begin{tabular}{|c|c|c|c|c|c|c|c|}
\hline $\begin{array}{l}\text { Flow } \\
\left(\mathrm{m}^{3} \mathrm{~s}^{-1}\right)\end{array}$ & $\begin{array}{l}\text { Mean } \\
\mu(\mathrm{m})\end{array}$ & $\begin{array}{c}\mathrm{SD} \\
\sigma(\mathrm{m})\end{array}$ & $\begin{array}{l}\mathrm{COV} \\
=\sigma / \mu\end{array}$ & $\begin{array}{l}\text { Min. value } \\
\text { (m) }\end{array}$ & $\begin{array}{l}\text { Max. value } \\
\text { (m) }\end{array}$ & PDF & $\chi^{2}$ \\
\hline 200 & 3.22 & 0.3296 & 0.10 & 2.17 & 3.83 & $\begin{array}{l}\text { Beta Gen. } \\
\text { Triang. } \\
\text { Normal }\end{array}$ & $\begin{array}{l}87.79 \\
117.5 \\
136.8\end{array}$ \\
\hline 300 & 3.68 & 0.3292 & 0.09 & 2.63 & 4.34 & $\begin{array}{l}\text { Beta Gen. } \\
\text { Triang. } \\
\text { Normal }\end{array}$ & $\begin{array}{l}71.26 \\
71.43 \\
146.5\end{array}$ \\
\hline 500 & 4.30 & 0.3398 & 0.08 & 3.21 & 5.11 & $\begin{array}{l}\text { Beta Gen. } \\
\text { Triang. } \\
\text { Normal }\end{array}$ & $\begin{array}{l}108.8 \\
140.5 \\
131.1\end{array}$ \\
\hline
\end{tabular}

the distributions adapted to water depth and velocity pass the test for the selected significance levels, thus showing poor fitting, even for this simple hydraulic model.

Given that bed friction coefficients $n_{i}$ are defined as random variables with bounded distributions, the water depth $y$ derived from the model is another random variable with a bounded distribution, with range $\left[y_{\text {MIN }}, y_{\text {MAX }}\right]$. These limiting values can be calculated straightforwardly from the model. A transformation of the water depth random variable, $y$, into another random variable, $w$, is proposed according to

$w=y_{\mathrm{MAX}}-y$.

Now $w$ is a bounded random variable, with positive skewness and confined in the range $\left[0, y_{\mathrm{MAX}}-y_{\mathrm{MIN}}\right]$. The 1000 realisations of $y$ obtained with Monte Carlo have been transformed according to Eq. (25) and new adaptations have been performed. Candidate probability distributions have been filtered relaxing the upper bound restriction to let upper unbounded distributions such as the lognormal to be fitted. The results obtained show an improvement in the fitting, particularly when $n_{i}$ friction values are normally distributed. In Fig. 4 a comparison of lognormal distributions fitted to calculated values is shown. The lognormal distributions fitted do not pass the $\chi^{2}$ goodness of fit test, mainly due to the inaccuracy in the adaptation of the upper tail. This was somehow expected as the lognormal is an upper unbounded distribution while $w$ is a bounded random variable. Still, it is interesting to see from the graphs in Fig. 4 that the lognormal distribution fits reasonably well for low $w$ values, which correspond to high $y$ values. An advantage of the lognormal distribution is that it is completely defined by only two parameters, its mean and standard deviation. The importance of this feature will be addressed later.

The convergence of results of mean and standard deviation values for water depth and velocity obtained with Monte Carlo simulation is shown in Fig. 5 for the case of $n_{i}$ uniformly distributed and case flow $500 \mathrm{~m}^{3} \mathrm{~s}^{-1}$. In this case, the estimated mean value of the water depth is $4.27 \mathrm{~m}$ and the $95 \%$ confidence interval is $[4.24 ; 4.30]$. The estimated mean value of the velocity is $1.81 \mathrm{~m} \mathrm{~s}^{-1}$ and the $95 \%$ confidence interval is $[1.77 ; 1.85]$. Taking into account the short amplitude of these intervals, a good approximation to the unknown asymptotic value is achieved. Similar results have been obtained for the rest of the cases of $n_{i}$ distributions and flow values, so they have not been included here. 
Table 5. Uniform flow model. Adaptation of PDFs to velocity with uniform distributions for $n_{i}$ (1000 simulations).

\begin{tabular}{|c|c|c|c|c|c|c|c|}
\hline $\begin{array}{l}\text { Flow } \\
\left(\mathrm{m}^{3} \mathrm{~s}^{-1}\right)\end{array}$ & $\begin{array}{c}\text { Mean } \\
\mu\left(\mathrm{ms}^{-1}\right)\end{array}$ & $\begin{array}{c}\mathrm{SD} \\
\sigma\left(\mathrm{m} \mathrm{s}^{-1}\right)\end{array}$ & $\begin{array}{l}\mathrm{COV} \\
=\sigma / \mu\end{array}$ & $\begin{array}{l}\text { Min. value } \\
\left(\mathrm{m} \mathrm{s}^{-1}\right)\end{array}$ & $\begin{array}{l}\text { Max. value } \\
\left(\mathrm{m} \mathrm{s}^{-1}\right)\end{array}$ & PDF & $\chi^{2}$ \\
\hline 200 & 1.72 & 0.5494 & 0.32 & 1.01 & 3.08 & $\begin{array}{l}\text { Beta Gen. } \\
\text { Triang. } \\
\text { Normal }\end{array}$ & $\begin{array}{l}115.6 \\
106.8 \\
486.9\end{array}$ \\
\hline 300 & 1.78 & 0.6580 & 0.37 & 0.97 & 3.36 & $\begin{array}{l}\text { Beta Gen. } \\
\text { Triang. } \\
\text { Normal }\end{array}$ & $\begin{array}{l}157.8 \\
170.9 \\
585\end{array}$ \\
\hline 500 & 1.81 & 0.6442 & 0.36 & 1.04 & 3.68 & $\begin{array}{l}\text { Beta Gen. } \\
\text { Triang. } \\
\text { Normal }\end{array}$ & $\begin{array}{l}217.1 \\
190.2 \\
721.8\end{array}$ \\
\hline
\end{tabular}
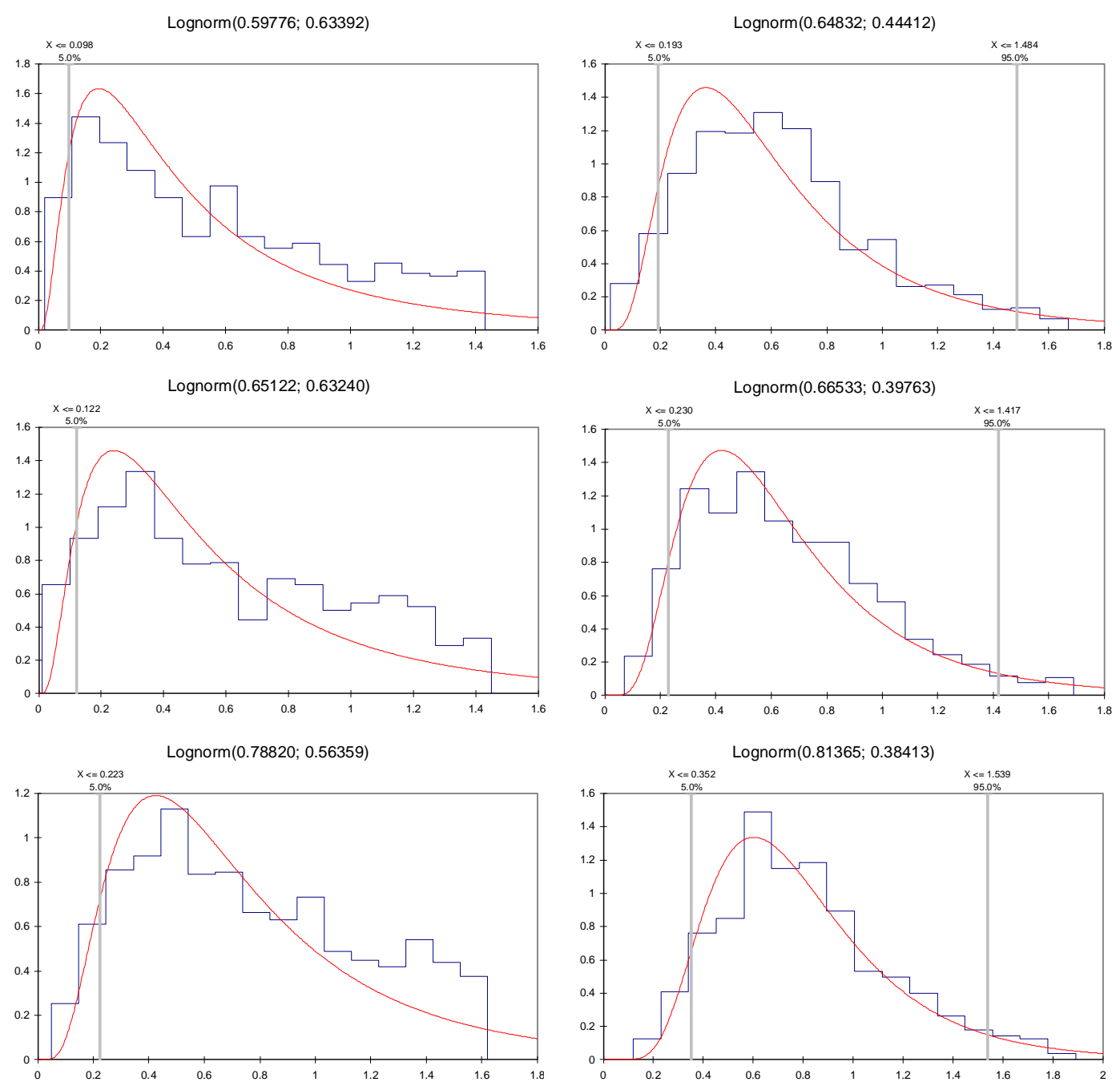

Fig. 4. Uniform flow model. Adaptation of lognormal PDF to transformed water depth variable $\left(w=y_{\mathrm{MAX}}-y\right)$ for $n_{i}$ uniformly distributed (left panels) and normally distributed (right panels), and for flow cases $200 \mathrm{~m}^{3} \mathrm{~s}^{-1}$ (top panels), $300 \mathrm{~m}^{3} \mathrm{~s}^{-1}$ (middle panels) and $500 \mathrm{~m}^{3} \mathrm{~s}^{-1}$ (bottom panels). 
Table 6. Uniform flow model. Adaptation of PDFs to velocity with triangular distributions for $n_{i}$ (1000 simulations).

\begin{tabular}{|c|c|c|c|c|c|c|c|}
\hline $\begin{array}{l}\text { Flow } \\
\left(\mathrm{m}^{3} \mathrm{~s}^{-1}\right)\end{array}$ & $\begin{array}{c}\text { Mean } \\
\mu\left(\mathrm{m} \mathrm{s}^{-1}\right)\end{array}$ & $\begin{array}{c}\mathrm{SD} \\
\sigma\left(\mathrm{m} \mathrm{s}^{-1}\right)\end{array}$ & $\begin{array}{l}\mathrm{COV} \\
=\sigma / \mu\end{array}$ & $\begin{array}{l}\text { Min. value } \\
\left(\mathrm{m}^{-1}\right)\end{array}$ & $\begin{array}{l}\text { Max. value } \\
\left(\mathrm{m} \mathrm{s}^{-1}\right)\end{array}$ & PDF & $\chi^{2}$ \\
\hline 200 & 1.67 & 0.3625 & 0.22 & 1.01 & 3.08 & $\begin{array}{l}\text { Beta Gen. } \\
\text { Triang. } \\
\text { Normal }\end{array}$ & $\begin{array}{r}65.4 \\
183.7 \\
160.9\end{array}$ \\
\hline 300 & 1.67 & 0.2033 & 0.12 & 0.97 & 3.36 & $\begin{array}{l}\text { Beta Gen. } \\
\text { Triang. } \\
\text { Normal }\end{array}$ & $\begin{array}{l}93.07 \\
146.5 \\
270.6\end{array}$ \\
\hline 500 & 1.64 & 0.3959 & 0.24 & 1.04 & 3.68 & $\begin{array}{l}\text { Beta Gen. } \\
\text { Triang. } \\
\text { Normal }\end{array}$ & $\begin{array}{l}147.6 \\
536.5 \\
351.2\end{array}$ \\
\hline
\end{tabular}
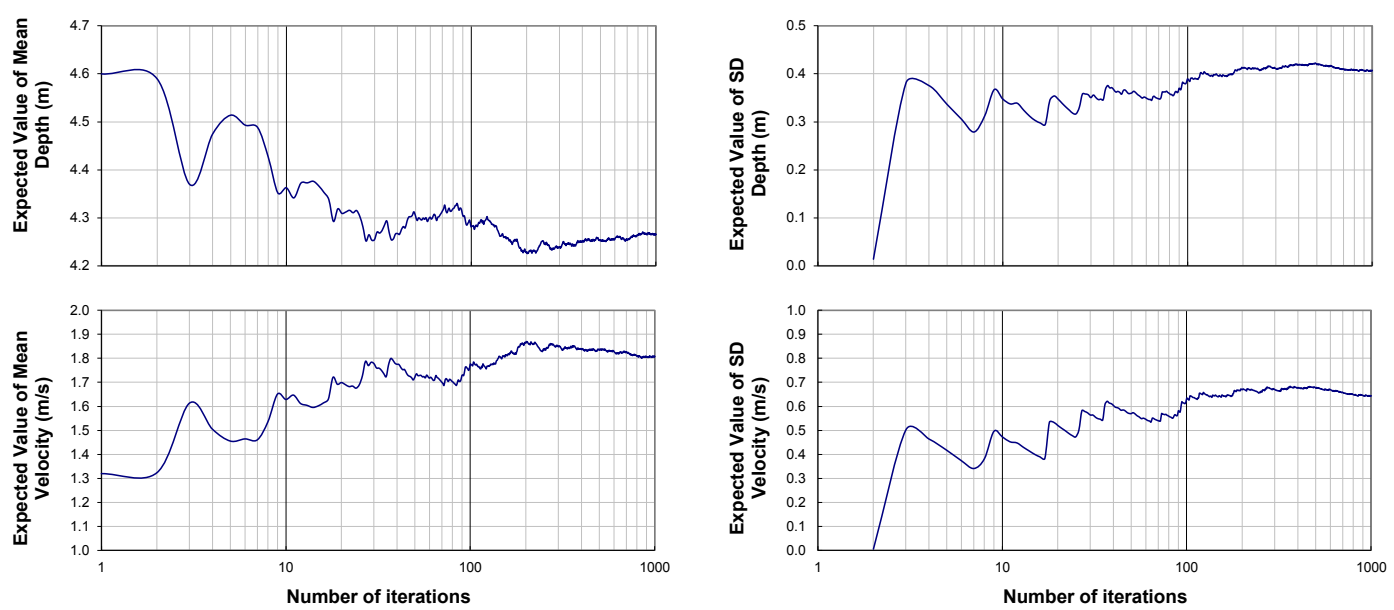

Fig. 5. Uniform flow model. Convergence of mean and standard deviation values for water depth and velocity. Case of $n_{i}$ uniformly distributed and flow case $500 \mathrm{~m}^{3} \mathrm{~s}^{-1}$.

\subsection{Uniform flow model - point-estimate method approximation}

To apply the point-estimate method the first step has been to identify the $2^{m}$ points where the performance function has to be evaluated, being $m$ the number of random variables, which are three in this case. The different probability distributions of the bed friction coefficient considered are symmetrical and roughness values in the three zones defined are assumed to be uncorrelated, although correlation can be easily included as shown in Sect. 2. Applying Eqs. (9) to (12) it can be seen that the two points per variable are located one standard deviation above or below the mean. In this case $m=3$ and we had $2^{3}=8$ points where the performance function had to be evaluated $\left(n_{1+}, n_{2+}, n_{3+}\right),\left(n_{1+}, n_{2+}, n_{3-}\right),\left(n_{1+}, n_{2-}, n_{3+}\right)$, $\left(n_{1+}, n_{2-}, n_{3-}\right),\left(n_{1-}, n_{2+}, n_{3+}\right),\left(n_{1-}, n_{2+}, n_{3-}\right),\left(n_{1-}\right.$, $\left.n_{2-}, n_{3+}\right),\left(n_{1-}, n_{2-}, n_{3-}\right)$. According to Eqs. (13) and (14) the probability or weight of each point is $P_{i}=0.125$. In Table 9 the corresponding values of $n_{i+}$ and $n_{i-}$ for each zone and distribution are summarized. The mean and variance of the water depth $y$ and velocity $v$ have been calculated with Eqs. (17) to (20), solving the model at the 8 points defined.

The comparison of the results obtained with the three probability distributions of the bed friction coefficient considered is shown in Fig. 6. Each dot on the chart corresponds to a different flow case. It can be observed that point-estimate gives almost exact estimates of the mean water depth values and provides a good approximation of velocities. The standard deviations show some scatter but still a reasonably good estimation is obtained. In summary, point-estimate provides a good approach for mean and standard deviation values of water depth and velocity with a very limited calculation effort.

\subsection{1-D HEC-RAS model}

A similar procedure has been followed using the 1D HEC RAS model of the river reach. A difference from the previous case is that in this case only uniform probability distributions for bed friction coefficients have been considered. The hydraulic model comprises the whole river reach, 
Table 7. Uniform flow model. Adaptation of PDFs to water depth with normal distributions for $\mathrm{n}_{i}$ (1000 simulations).

\begin{tabular}{|c|c|c|c|c|c|c|c|}
\hline $\begin{array}{l}\text { Flow } \\
\left(\mathrm{m}^{3} \mathrm{~s}^{-1}\right)\end{array}$ & $\begin{array}{l}\text { Mean } \\
\mu(\mathrm{m})\end{array}$ & $\begin{array}{c}\mathrm{SD} \\
\sigma(\mathrm{m})\end{array}$ & $\begin{array}{l}\mathrm{COV} \\
=\sigma / \mu\end{array}$ & $\begin{array}{l}\text { Min. value } \\
\text { (m) }\end{array}$ & $\begin{array}{l}\text { Max. value } \\
\text { (m) }\end{array}$ & PDF & $\chi^{2}$ \\
\hline 200 & 1.72 & 0.4730 & 0.27 & 0.96 & 3.47 & $\begin{array}{l}\text { Beta } \\
\text { Triang. } \\
\text { Normal }\end{array}$ & $\begin{array}{l}76.83 \\
156.1 \\
182\end{array}$ \\
\hline 300 & 1.74 & 0.5670 & 0.33 & 0.93 & 3.83 & $\begin{array}{l}\text { Beta } \\
\text { Triang. } \\
\text { Normal }\end{array}$ & $\begin{array}{l}120.5 \\
194.6 \\
367.8\end{array}$ \\
\hline 500 & 1.71 & 0.5412 & 0.32 & 1.004 .29 & Beta & $\begin{array}{l}221.4 \\
\text { Triang. } \\
\text { Normal }\end{array}$ & $\begin{array}{l}633 \\
563.7\end{array}$ \\
\hline
\end{tabular}
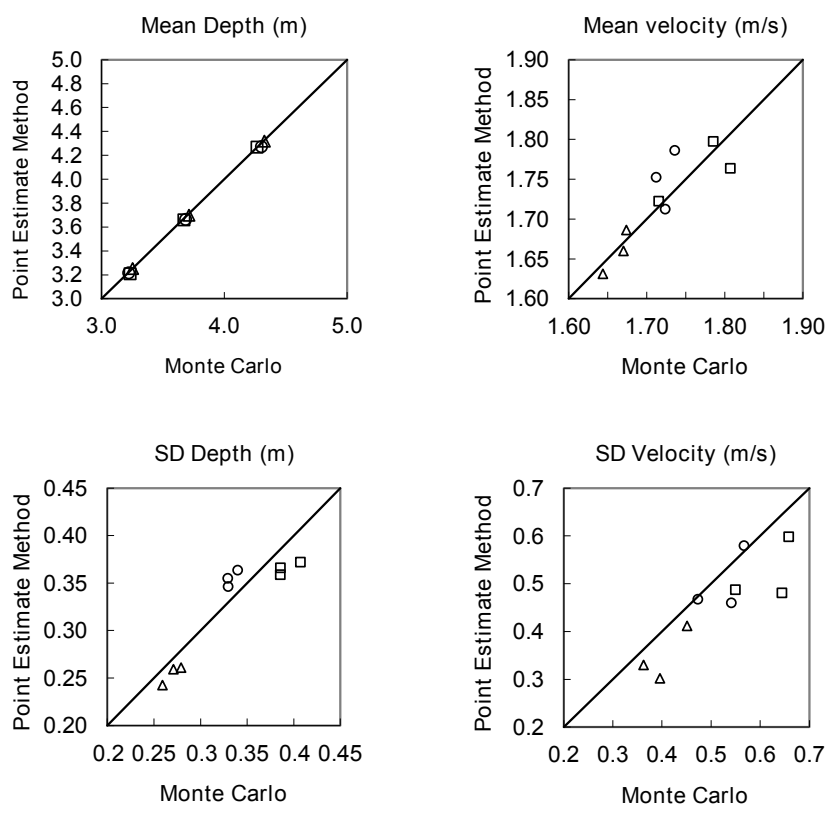

Fig. 6. Uniform flow model. Mean and standard deviations of water depth and velocity predicted by point-estimate method against Monte Carlo. Results for $n_{i}$ distributions: uniform (squares), normal (circles) and triangular (triangles). Each point on the chart corresponds to a flow case.

allowing for changes in section and slope, and so adding non linear effects to the problem with respect to the uniform flow model. Values of water depth and velocity are obtained at the 12 river stations defined in the model. The Monte Carlo analysis has been limited to 100 simulations, which are sufficient to get a good estimation of the mean and standard deviation values of water depth and velocity, as can be seen by the convergence curves shown in Fig. 7 for cross section at river station RS 768 and flow case $500 \mathrm{~m}^{3} \mathrm{~s}^{-1}$. In this case the estimated mean water depth is $y=4.37 \mathrm{~m}$, and the $95 \%$ confidence interval that corresponds to 100 simulations is $[4.33 ; 4.41]$. The length of the interval is $0.08 \mathrm{~m}$, which is considered enough accuracy for the purpose of this paper. As a reference, interval lengths of 0.20 and $0.02 \mathrm{~m}$ would be expected for 10 and 1000 simulations, respectively. Similar results have been obtained for the other cross sections and flow cases so they are not shown here.

The point-estimate method needed only 8 calculations of the hydraulic model for each flow case. The comparison of results obtained with Monte Carlo and point-estimate method is shown in Figs. 8 to 10 for the three flow cases considered. Each dot on the chart corresponds to a different river cross section. It can be seen that the mean depth is well approximated by point-estimate for almost all cross sections. For flow cases of 300 and $500 \mathrm{~m}^{3} \mathrm{~s}^{-1}$ the mean depth is slightly underestimated by point-estimate method. For example, at RS 768 the point-estimate method gives a mean water depth $y=4.34 \mathrm{~m}$. This fact shows the appearance of non linear effects and the influence of the whole reach in the flow characteristics of different sections of the model. The standard deviation of the water depth is reasonably well estimated, showing some scatter for different flow rates and different cross sections. For example, at RS 768 the standard deviation of water depth estimated with Monte Carlo has a value of $0.1954 \mathrm{~m}$ while point-estimate gives a value of $0.1986 \mathrm{~m}$. The mean velocity is slightly overestimated by point-estimate method though values fit reasonably well with those obtained with Monte Carlo. The standard deviation for velocity shows good performance. A comparison of mean and standard deviation of flow profiles for flow case $500 \mathrm{~m}^{3} \mathrm{~s}^{-1}$ is shown in Fig. 11.

Flood uncertainty can be depicted by raster maps of mean and standard deviation of water level values. In Fig. 12 flood inundation maps of the analysed river reach with mean water depths for the three flow cases are shown. In Fig. 13 the raster map of standard deviation of water levels is shown, where the 1-D mathematical structure of the model is highlighted by the alignment of the standard deviation bands parallel to the cross section definition in HEC-RAS model. The pattern reproduced is that of Fig. 11. 
Table 8. Uniform flow model. Values of $\chi^{2}$ statistic.

\begin{tabular}{llcccc}
\hline $\begin{array}{l}\text { Significance } \\
\text { level }(\alpha)\end{array}$ & PDF fitted & $\begin{array}{c}\text { Number of } \\
\text { parameters } \\
(m)\end{array}$ & $\begin{array}{c}\text { Number of bins } \\
\text { used in the test } \\
(b)\end{array}$ & $\begin{array}{c}\text { Degrees of } \\
(b-1-m) \\
\text { freedom }\end{array}$ & $\chi^{2}$ \\
\hline 0.05 & Beta general & 4 & 29 & 24 & 36.42 \\
& Triangular & 3 & 29 & 25 & 37.65 \\
& Normal & 2 & 29 & 26 & 38.89 \\
0.01 & Beta general & 4 & 29 & 24 & 42.98 \\
& Triangular & 3 & 29 & 25 & 44.31 \\
& Normal & 2 & 29 & 26 & 45.64 \\
\hline
\end{tabular}
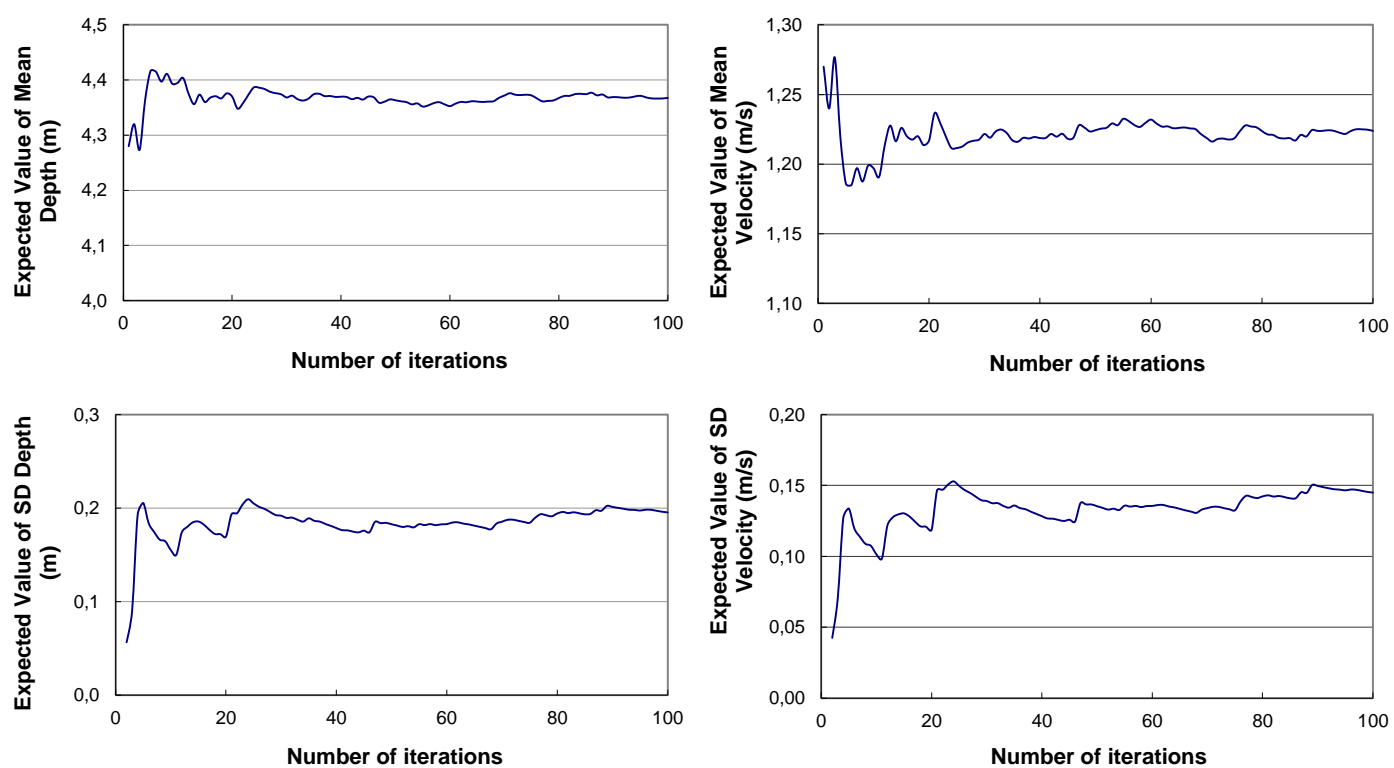

Fig. 7. 1-D HEC-RAS model. Convergence of mean and standard deviation values for water depth and velocity at RS 768. Case of $n_{i}$ uniformly distributed with flow case $500 \mathrm{~m}^{3} \mathrm{~s}^{-1}$.

Table 9. Points estimate method. Values of bed friction used to evaluate the performance function.

\begin{tabular}{llcc}
\hline PDF of $n_{i}$ & Zone of $n_{i}$ & $\begin{array}{c}x_{i-\text { point: }} \\
\mu-\sigma\end{array}$ & $\begin{array}{c}x_{i+\text { point: }} \\
\mu+\sigma\end{array}$ \\
\hline \multirow{2}{*}{ Uniform } & Left overbank & 0.045 & 0.085 \\
& Channel & 0.031 & 0.059 \\
\multirow{5}{*}{ Triangular } & Right overbank & 0.053 & 0.117 \\
& Left overbank & 0.051 & 0.079 \\
& Channel & 0.035 & 0.055 \\
& Right overbank & 0.063 & 0.107 \\
& Left overbank & 0.045 & 0.085 \\
& Channel & 0.031 & 0.059 \\
& Right overbank & 0.053 & 0.117 \\
\hline
\end{tabular}

\section{Application to 2-D model}

In this Section the application of the point-estimate method in combination with a 2-D shallow water equations model is presented. Only uniform probability distributions have been considered for the roughness values of channel and overbanks, in a similar fashion as with 1-D HEC-RAS model.

The 2-D hydraulic model had to been run 8 times, according to the 8 combinations of the three random variables point values adopted, for each of the 3 flow cases, so initially 24 runs were needed. To optimize the process a hydrograph with three steps with constant flow rates of 200, 300 and $500 \mathrm{~m}^{3} \mathrm{~s}^{-1}$ has been prepared, reducing the number of model runs from 24 to 8 . The duration of each constant flow step has been set to allow the model to reach a steady state flow in the whole domain, resulting a duration of $30 \mathrm{~min}$ for each constant discharge step. Results are then retrieved and the calculations proceed to the next flow value. The time of calculation with the 2-D model implemented in the commercial 


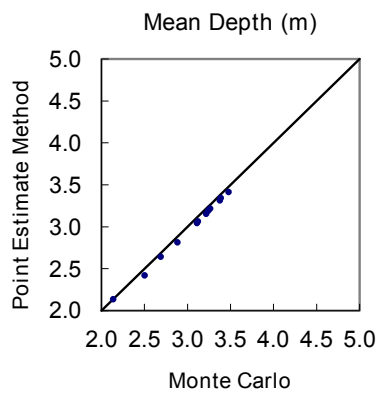

SD Depth $(m)$

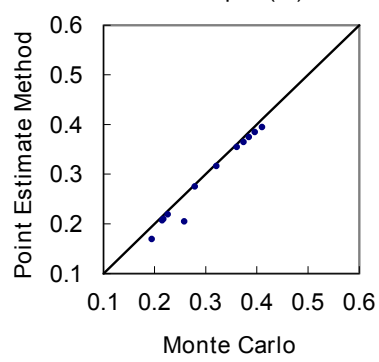

Mean velocity $(\mathrm{m} / \mathrm{s})$

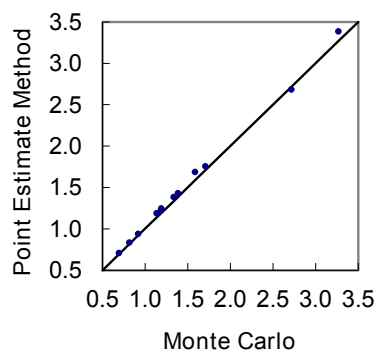

SD Velocity $(\mathrm{m} / \mathrm{s})$

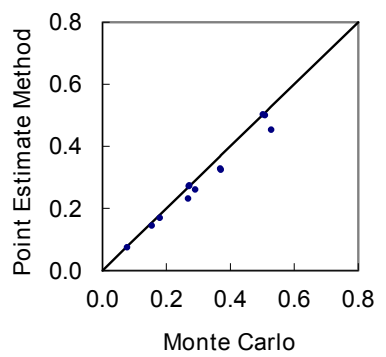

Fig. 8. 1-D HEC-RAS model. Mean and standard deviations of water depth and velocity predicted by point-estimate method against Monte Carlo. Results for $n_{i}$ uniformly distributed and flow case $200 \mathrm{~m}^{3} \mathrm{~s}^{-1}$. Each dot corresponds to a different RS of the model.
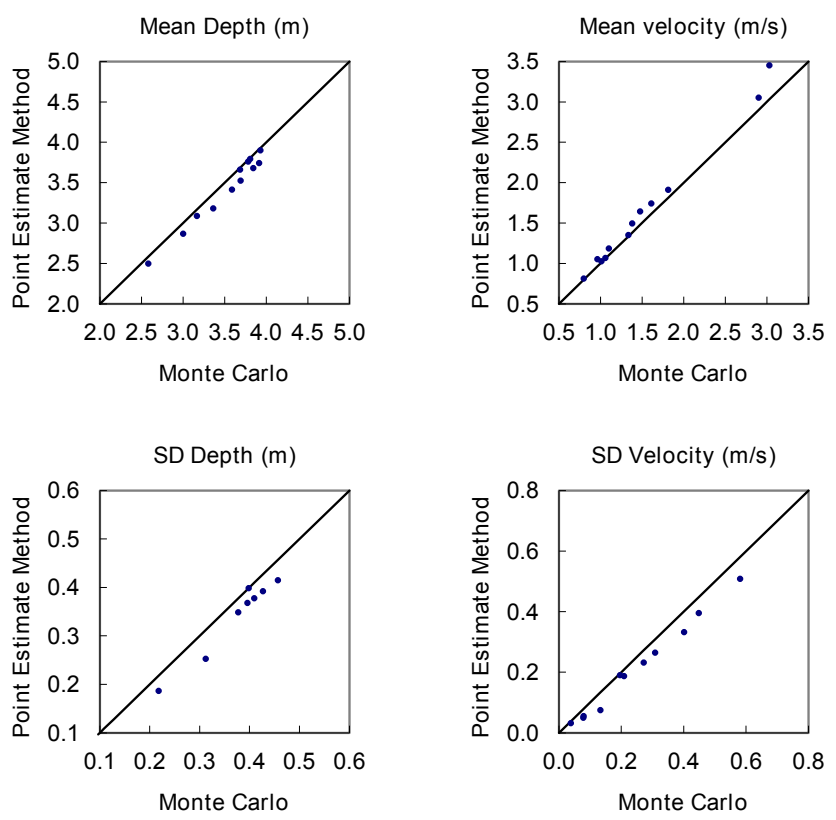

Fig. 9. 1-D HEC-RAS model. Mean and standard deviations of water depth and velocity predicted by point-estimate method against Monte Carlo. Results for $n_{i}$ uniformly distributed and flow case $300 \mathrm{~m}^{3} \mathrm{~s}^{-1}$. Each dot corresponds to a different RS of the model.
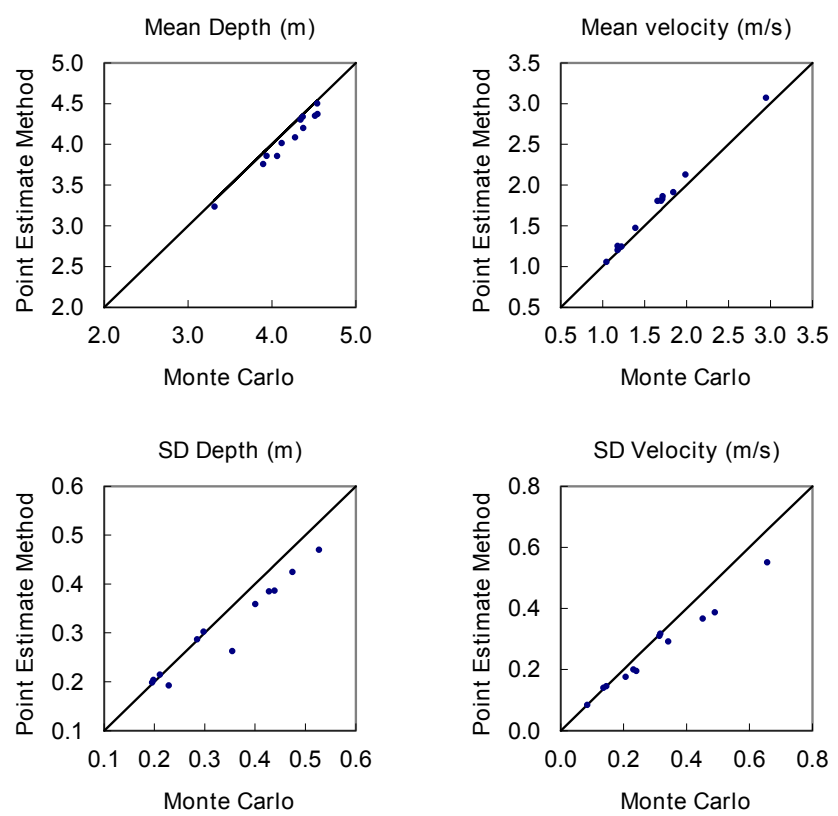

Fig. 10. 1-D HEC-RAS model. Mean and standard deviations of water depth and velocity predicted by point-estimate method against Monte Carlo. Results for $n_{i}$ uniformly distributed and flow case $500 \mathrm{~m}^{3} \mathrm{~s}^{-1}$. Each dot corresponds to a different RS of the model.

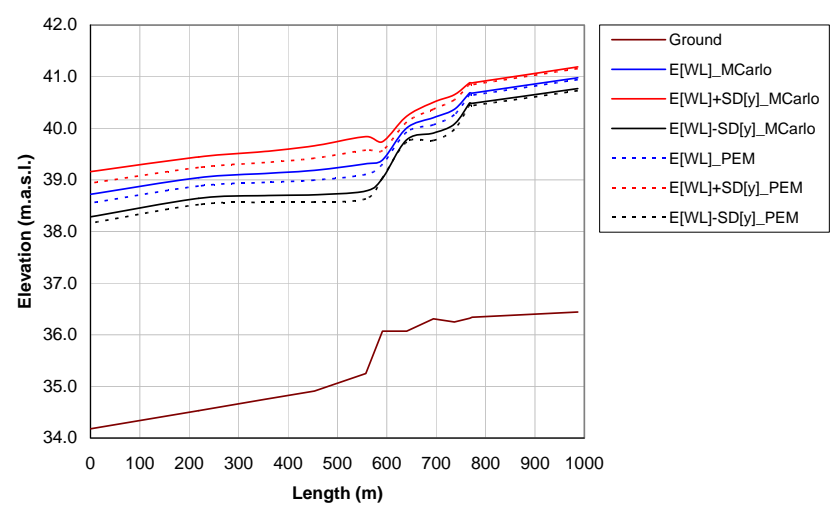

Fig. 11. 1-D HEC-RAS model. Comparison of water profiles for case flow $500 \mathrm{~m}^{3} \mathrm{~s}^{-1}$. Mean and standard deviation values estimated with Monte Carlo and point-estimate method.

code GUAD-2-D is considerably longer that with 1-D models. Each run of the HEC-RAS model takes less than $1 \mathrm{~s}$ while each run of the GUAD-2-D model has had an average time duration of $5 \mathrm{~h}$, which makes flood uncertainty analysis with Monte Carlo unfeasible from a practical point of view in engineering. Still, an approximate uncertainty analysis can be performed with the help of the point-estimate method.

The first step has been to perform the calculations with the 2-D hydraulic model at the 8 points where the performance functions have to be evaluated. In this case the performance functions are the water depth and the total velocity at 


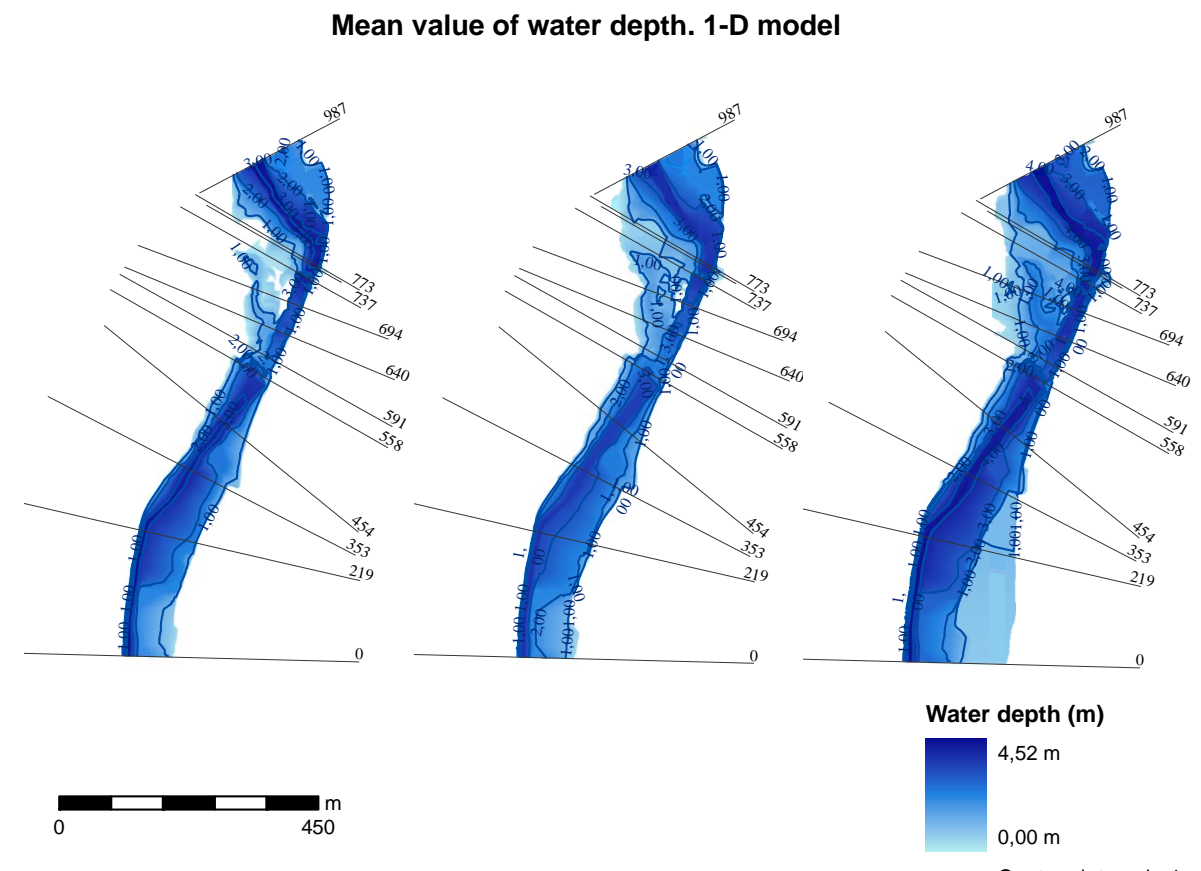

Fig. 12. 1-D HEC-RAS model. Flood maps with mean values of water depth predicted by point-estimate method for flow cases of $200 \mathrm{~m}^{3} \mathrm{~s}^{-1}$ (left panel), $300 \mathrm{~m}^{3} \mathrm{~s}^{-1}$ (middle panel) and $500 \mathrm{~m}^{3} \mathrm{~s}^{-1}$ (right panel).

\section{Standard deviation of water depth. 1-D model}

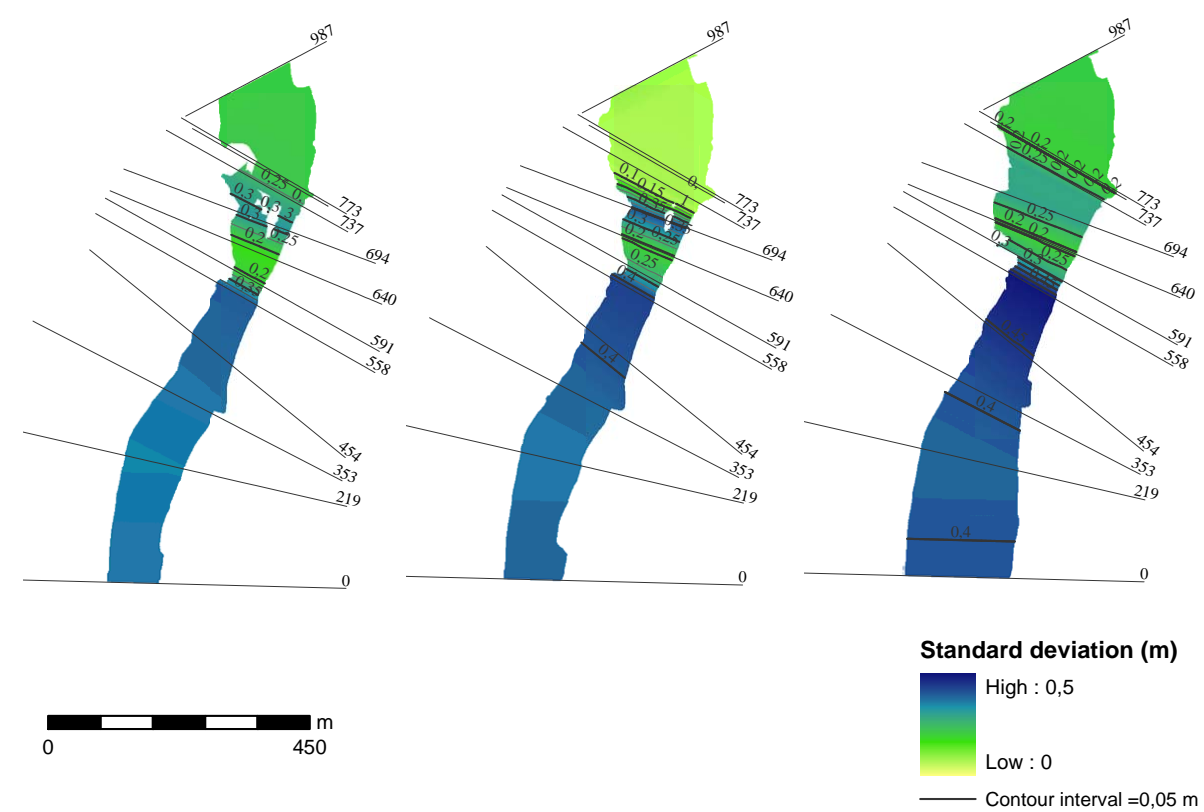

Fig. 13. 1-D HEC-RAS model. Flood maps with standard deviation values of water depth predicted by point-estimate method for flow cases of $200 \mathrm{~m}^{3} \mathrm{~s}^{-1}$ (left panel), $300 \mathrm{~m}^{3} \mathrm{~s}^{-1}$ (middle panel) and $500 \mathrm{~m}^{3} \mathrm{~s}^{-1}$ (right panel).

every $1 \times 1 \mathrm{~m}$ cell of the model. In this case the total velocity value has been selected though the analysis can be done separately for its components $\left(v_{X}, v_{Y}\right)$. Series of raster maps with the results of water depths and velocities evaluated for the 8 combinations of roughness coefficients are stored in a GIS framework. The mathematical operations defined in Eqs. (18) to (20) have been performed within the GIS using the generated layers with GUAD 2-D. The first two moments about the origin of the performance functions are calculated at every point of the grid, and from those the expected value 


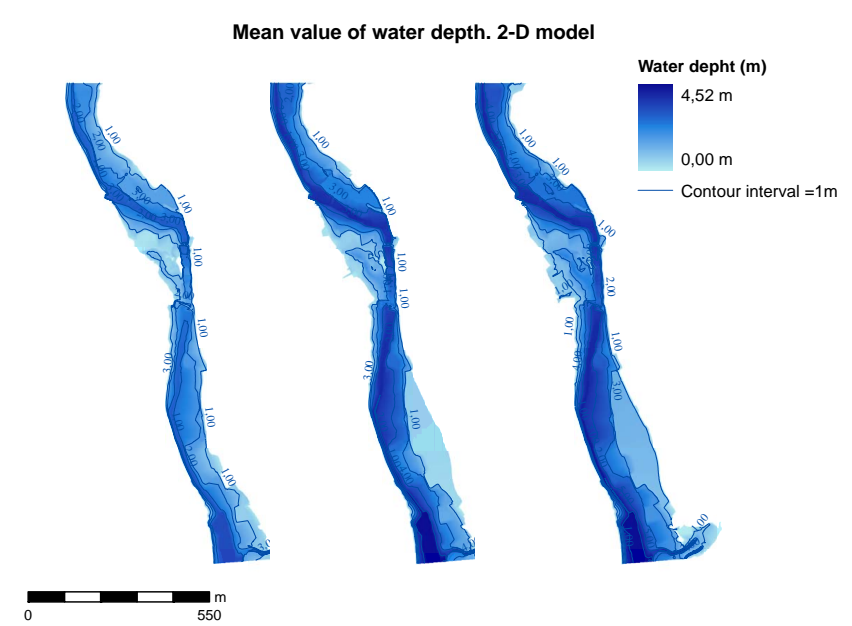

Fig. 14. 2-D SWE model. Flood maps with mean values of water depth predicted by point-estimate method for flow cases of $200 \mathrm{~m}^{3} \mathrm{~s}^{-1}$ (left panel), $300 \mathrm{~m}^{3} \mathrm{~s}^{-1}$ (middle panel) and $500 \mathrm{~m}^{3} \mathrm{~s}^{-1}$ (right panel).

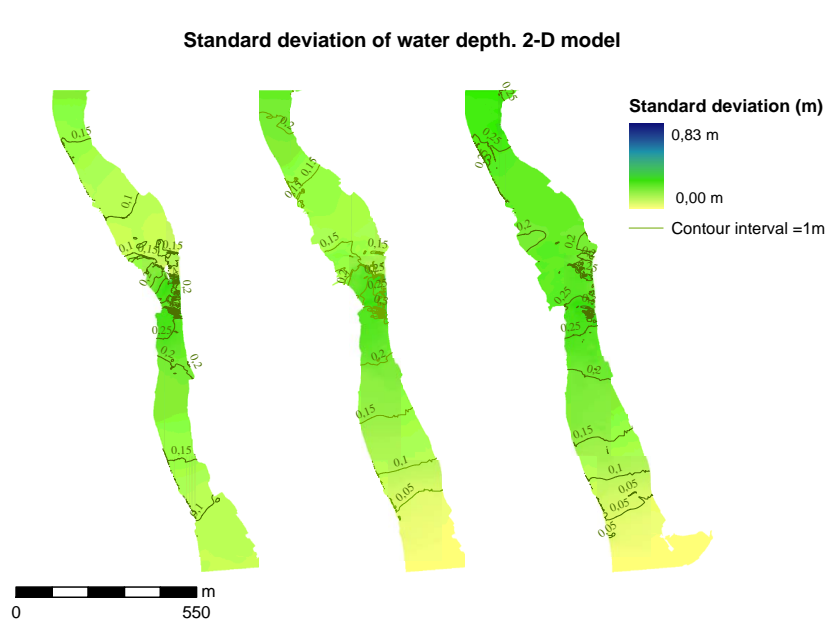

Fig. 15. 2-D SWE model. Flood maps with standard deviation values of water depth predicted by point-estimate method for flow cases of $200 \mathrm{~m}^{3} \mathrm{~s}^{-1}$ (left panel), $300 \mathrm{~m}^{3} \mathrm{~s}^{-1}$ (middle panel) and $500 \mathrm{~m}^{3} \mathrm{~s}^{-1}$ (right panel).

and the standard deviation are derived. The flood map with expected values of water depth for the three flow cases is shown in Fig. 14. The standard deviations of water depth can be seen in Fig. 15, where the 2-D mathematical structure of the model becomes clear when compared with equivalent map obtained with HEC-RAS model. The map of mean and standard deviation of velocities of flow is shown in Figs. 16 and 17 , respectively.

Results from 2-D models can be used to assess the extension of flooded areas with different severity levels. The flood severity levels are defined in terms of flood depth, velocity and dragging coefficient, which is defined as the product of the water depth times the velocity. An example of a chart

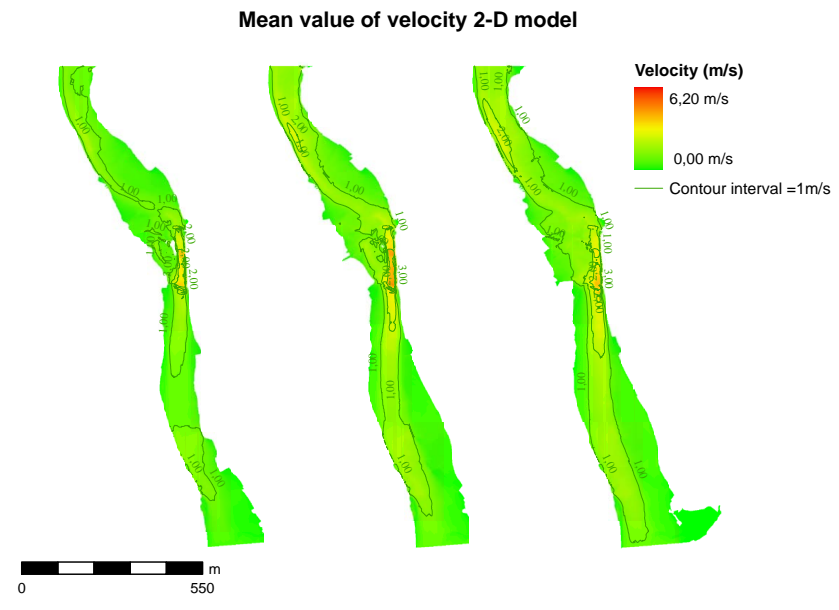

Fig. 16. 2-D SWE model. Flood maps with mean values of velocity predicted by point-estimate method for flow cases of $200 \mathrm{~m}^{3} \mathrm{~s}^{-1}$ (left panel), $300 \mathrm{~m}^{3} \mathrm{~s}^{-1}$ (middle panel) and $500 \mathrm{~m}^{3} \mathrm{~s}^{-1}$ (right panel).

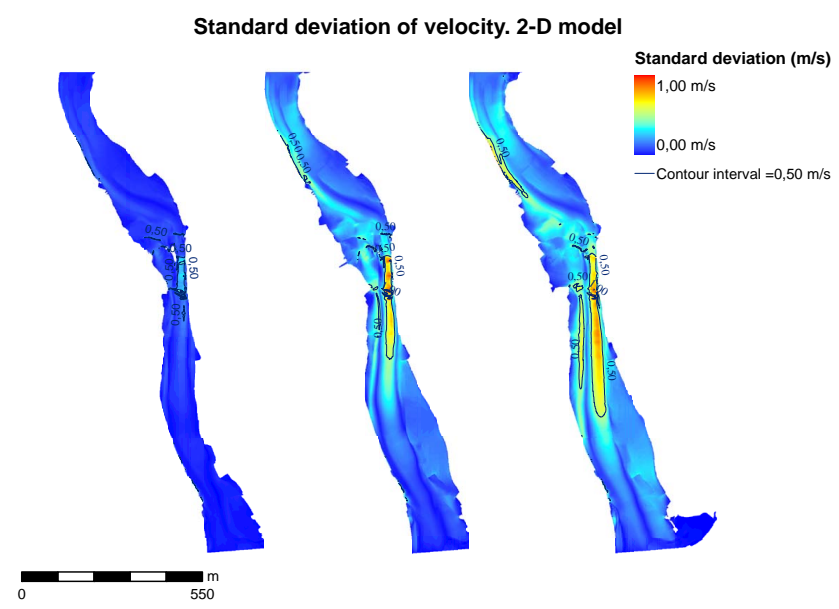

Fig. 17. 2-D SWE model. Flood maps with standard deviation values of velocities predicted by point-estimate method for flow cases of $200 \mathrm{~m}^{3} \mathrm{~s}^{-1}$ (left panel), $300 \mathrm{~m}^{3} \mathrm{~s}^{-1}$ (middle panel) and $500 \mathrm{~m}^{3} \mathrm{~s}^{-1}$ (right panel).

for flood severity levels is shown in Fig. 18 (Gracia et al., 2010). In this case 5 severity levels are defined as low (1), moderate (2), high (3), very high (4) and extremely high (5), according to Table 10. Flood severity levels are used to estimate fatalities and/or economic losses. The severity analysis has not been performed with the 1-D model because the velocity distribution along each cross section is too rough to allow meaningful comparisons with 2-D model in terms of severity.

For each flow case, every point of the flooded area has been evaluated in terms of water depth, velocity and dragging coefficient for the 8 runs of the 2-D model. With the help of GIS tools, the corresponding severity level has been derived for each $1 \mathrm{~m}^{2}$ cell using the criteria defined in Fig. 18. The 


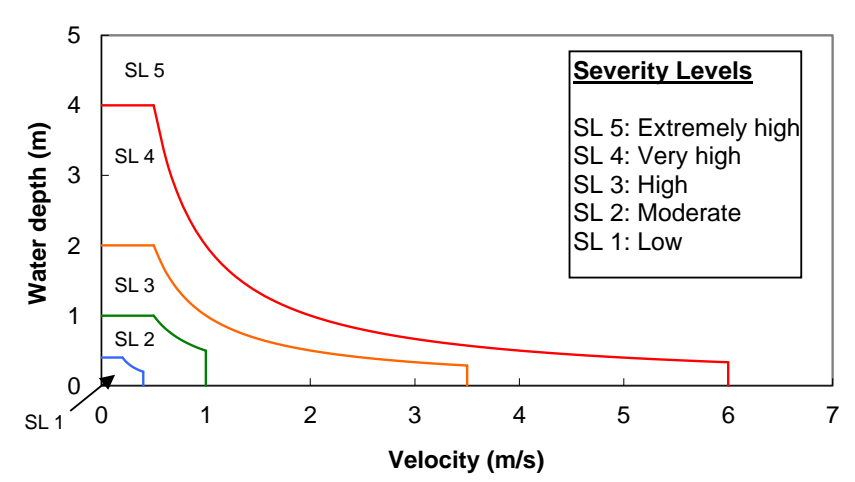

Fig. 18. Flood severity levels (adapted from Gracia et al., 2010).

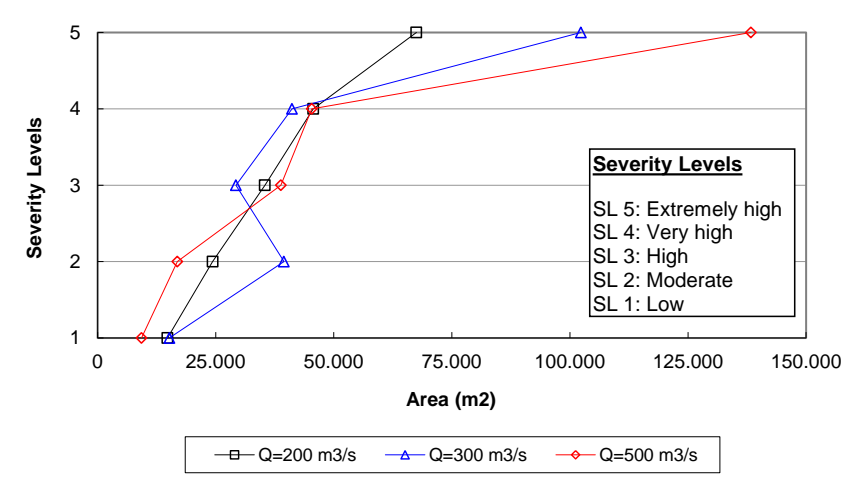

Fig. 19. 2-D SWE model. Expected values of the extension of areas with different severity levels for flow cases 200, 300 and $500 \mathrm{~m}^{3} \mathrm{~s}^{-1}$.

total area for every flood severity level was computed, obtaining 8 different values for each level. Following the procedure of the point-estimate method the mean and standard deviation of the extension of the flooded area for each severity level has been calculated.

The estimated mean values for each severity level and for the three flow cases are shown in Fig. 19. It can be seen that as discharge increases the extension of flooded areas with higher severity levels is generally incremented. In some cases, as discharge increases, flow over large floodplains with low water depths takes place. And additional increase in discharge increases water depths, changing the severity level of a large surface, while new flooded areas with low water depths have lesser extent. This is the case of severity levels 1 and 2 in Fig. 19. The estimated mean values and standard deviations of the extension of the flooded areas for each severity level is shown in Fig. 20 (flow case $200 \mathrm{~m}^{3} \mathrm{~s}^{-1}$ ), Fig. 21 (flow case $300 \mathrm{~m}^{3} \mathrm{~s}^{-1}$ ) and Fig. 22 (flow case $500 \mathrm{~m}^{3} \mathrm{~s}^{-1}$ ). It is interesting to see how the range of variation of extension of flooded areas varies for each severity level, bringing a measure of the uncertainty that can be easily transferred to consequence estimation in a risk analysis context. In the case flow $200 \mathrm{~m}^{3} \mathrm{~s}^{-1}$ it can be seen that higher uncertainty derived from roughness coefficient is present for severity levels

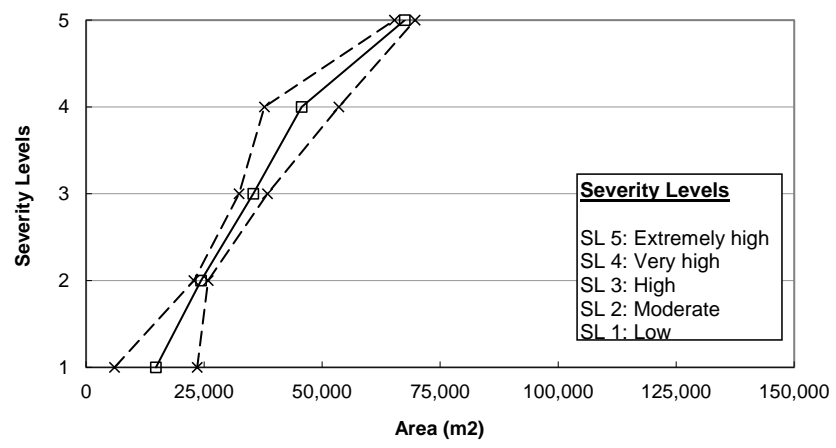

Fig. 20. 2-D SWE model. Expected values and standard deviations of the extension of areas with different severity levels for flow case $200 \mathrm{~m}^{3} \mathrm{~s}^{-1}$.

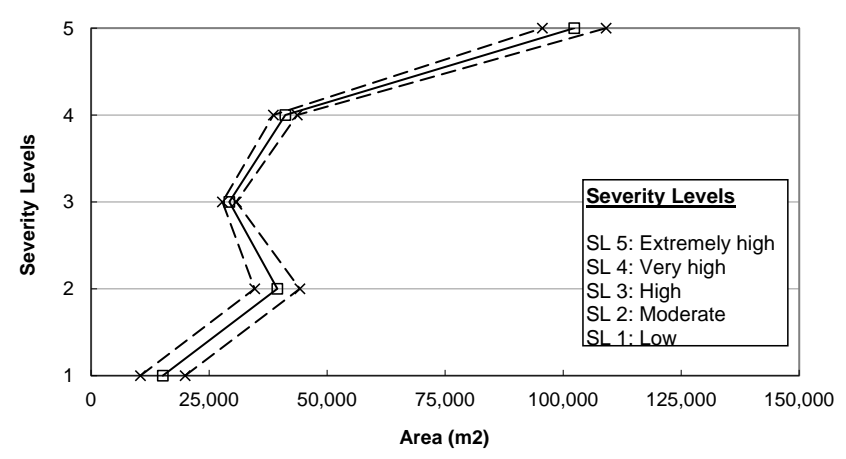

Fig. 21. 2-D SWE model. Expected values and standard deviations of the extension of areas with different severity levels for flow case $300 \mathrm{~m}^{3} \mathrm{~s}^{-1}$.

low (1) and high (3). For flow case $300 \mathrm{~m}^{3} \mathrm{~s}^{-1}$ low, uniform uncertainty is spread over all severity levels. On the other hand, for flow case $500 \mathrm{~m}^{3} \mathrm{~s}^{-1}$ a wider band of uncertainty is linked to severity levels high (3) and very high (4).

A normalized measure of the amount of uncertainty of a random parameter is the coefficient of variation, $\mathrm{COV}$, which is defined as the ratio between the standard deviation, $\sigma$, and the mean, $\mu$. Values of COV for each severity level for the three flow cases analyzed are depicted in Fig. 23. In engineering practice a small uncertainty would be represented by a $\mathrm{COV}=0.05$ while considerable uncertainty would be indicated by a COV $=0.25$ (Hoek, 2007). It can be seen that the majority of COV values obtained in the case study lie in the range $[0.05 ; 0.25]$, which means an intermediate situation where significant yet not too high uncertainty is present due to the variability assumed for the roughness coefficient.

The results in Figs. 20 to 22 show how the uncertainty in bed friction coefficient is transferred to flooded areas with different severity levels. This information may be useful in the risk analysis context when used in combination with the spatial distribution of vulnerability of the flooded area. This means that at least some of the uncertainty from the hydraulic 
Table 10. Flood severity levels.

\begin{tabular}{|c|c|c|c|}
\hline Severity level & $\begin{array}{l}\text { Range of water depth, } \\
y(\mathrm{~m})\end{array}$ & $\begin{array}{l}\text { Range of velocity, } \\
v\left(\mathrm{~m} \mathrm{~s}^{-1}\right)\end{array}$ & $\begin{array}{l}\text { Range of dragging } \\
\text { coefficient, } y \cdot v\left(\mathrm{~m}^{2} \mathrm{~s}^{-1}\right)\end{array}$ \\
\hline Low (1) & $y \leq 0.4$ & $v \leq 0.4$ & $y \cdot v \leq 0.08$ \\
\hline Moderate (2) & $0.4<y \leq 1$ & $0.4<v \leq 1$ & $0.08<y \cdot v \leq 0.5$ \\
\hline High (3) & $1<y \leq 2$ & $1<v \leq \overline{3} .5$ & $0.5<y \cdot v \leq 1$ \\
\hline Very high (4) & $2<y \leq 4$ & $3.5<v \leq 6$ & $1<y \cdot v \leq 2$ \\
\hline Extremely high (5) & $4<y$ & $6<v$ & $2<y \cdot v$ \\
\hline
\end{tabular}

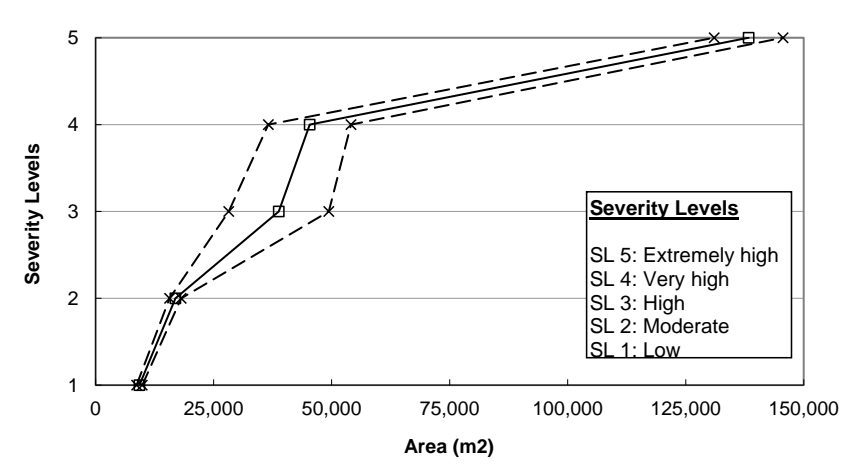

Fig. 22. 2-D SWE model. Expected values and standard deviations of the extension of areas with different severity levels for flow case $500 \mathrm{~m}^{3} \mathrm{~s}^{-1}$.

model can be added to the estimates of flood damage in the context of risk analysis.

From the point of view of the engineer that has to build a model, information regarding the location of zones with higher variability can be useful to make decisions, such as where to direct the efforts for efficient model improvement.

\section{Conclusions}

In the context of assessing the uncertainty in flood modelling in a river reach, the results presented have shown the practical applicability of the point-estimate method to perform uncertainty flood analysis, considering the Manning's $n$ roughness coefficient as the main source of uncertainty. Specific relationships between roughness coefficient and flow have not been considered. Reasonable estimates of mean and standard deviation values of flood parameters such as water depth and velocity have been obtained with much less effort than with Monte Carlo method using 1-D HEC RAS and a 2-D SWE model implemented in the commercial code GUAD 2-D. It has been shown that with a simple variable transformation the water depth parameter can be roughly approximated by a lognormal distribution. Better fitting is observed in the lower tail of the transformed variable which corresponds to the upper tail of the water depth distribution. As the lognormal distribution is fully defined by its mean and variance, a probabilistic characterization can be achieved using PEM.

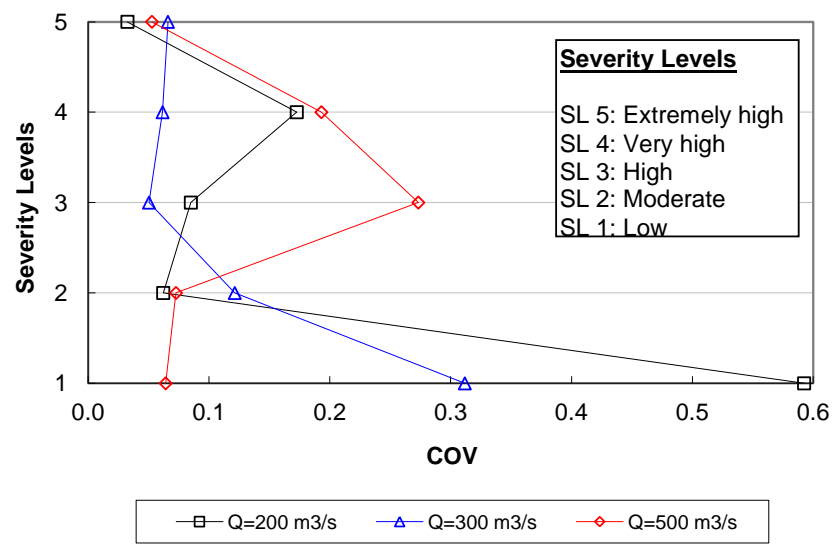

Fig. 23. 2-D SWE model. Coefficient of variation (COV) of the extension of the area foir each severity level.

When the 1-D HEC RAS model is used, a reasonably good approximation has been obtained with point-estimate method, as the results match well with those obtained with Monte Carlo method. Applicability to 2-D SWE model has been shown. To evaluate the soundness of the approximation additional research is needed, comparing the results of flood estimates obtained with those from a 2-D SWE using Monte Carlo method. This seems to be a promising field of research.

Flood maps with expected values of water depth and velocity and their associated standard deviations have been obtained implementing the point-estimate calculations within a GIS framework, and flooded areas with different associated severity levels have been calculated in terms of the expected values and standard deviations of their extension. As the evaluation of consequences of a flood in terms of fatalities and/or economic losses is achieved using rates linked to the extension of each severity level, in combination with the spatial distribution of vulnerability in the flooded area, uncertainty in the system response is transferred to the consequence evaluation.

The main limitations of point-estimate method are the loss of accuracy if the performance function cannot be approximated by third order polynomials and the fast growing of the number of calculations needed if the number of random variables $m$ increases, rendering the method impracticable for computing time-demanding problems, such as 2-D models. 
Though the method presented has some evident advantages such as its simplicity and limited effort needed to perform uncertainty analysis of floods with nonprobabilistically-oriented 2-D commercial codes, the results obtained should be carefully looked at. They should not be deemed as exact values and it should be kept in mind that this method is a practical alternative to more exact methods. It is acknowledged that more research is needed in order to set the limits of the applicability of the method and its accuracy in the 2-D models environment, above all when strong non-linearities are present in the model.

The method presented is not always the best choice, but it may be considered by engineers as a useful tool for screening analysis before restoring to more powerful but more costly methods in terms of time and money in the risk analysis context. It is recognized, though, that whenever Monte Carlo application is practically feasible, it is a preferred approach. The underlying approach that has been presented is in line with a quote by Box (Box and Draper, 1987), in the sense that all models are wrong, and that the practical question is how wrong they have to be to not be useful.

Acknowledgements. This work is part of the research project "Incorporacion de los componentes de riesgo antropico a los sistemas de gestion integral de seguridad de presas y embalses" BIA2010-17852, funded by Spain's Ministerio de Ciencia e Innovación and FEDER funds.

Edited by: G. Di Baldassarre

\section{References}

Aronica, G., Hankin, B., and Beven, K. J.: Uncertainty and equifinality in calibrating distributed roughness coefficients in a flood propagation model with limited data, Adv. Water Resour., 22, 349-365, 1998.

Berz, G.: Flood disaster: Lessons from the past-worries for the future, Water Manage. Mar. Eng., 142, 1-10, 2000.

Beven, K. J. and Binley, A.: The future of distributed models: model calibration and uncertainty prediction, Hydrol. Process., 6, 279298, 1992.

Bladé, E., Gómez, M., and Dolz, J.: Quasi-two dimensional modelling of flood routing in rivers and flood plains by means of storage cells, in: Modelling of Flood Propagation Over Initially Dry Areas, edited by: Molinaro, P. and Natal, L., American Society of Engineers, Milan, 1994.

Box, G. E. P. and Draper, N. R.: Empirical model building and response surfaces, Wiley, 1987.

CEDEX: IBER, Two-dimensional model of free surface shallow water flow, available at: http://www.iberaula.es/web/index.php (last access: 4 July 2012), 2010.

Cesare, M. A.: First order analysis of open-channel flow, J. Hydraul. Eng.-ASCE, 117, 242-247, 1991.

Christian, J. T. and Baecher, G. B.: Point-estimate method as numerical quadrature, J. Geotech. Geoenviron., 125, 779-786, 1999.
Cobby, D. M., Mason, D. C., and Davenport, I. J.: Image processing of airborne scanning laser altimetry data for improved river flood modelling, ISPRS J. Photogramm., 56, 121-138, 2001.

Cook, A. and Merwade, V.: Effect of topographic data, geometric configurations and modelling approach on flood inundation mapping, J. Hydrol., 377, 131-142, 2009.

DEFRA Department for Environment, Food and Rural Affairs: Draft Flood and Water Management Bill, Welsh Assembly Government, 2009.

Deltares: SOBEK, available at: http://www.deltaressystems.com/ hydro/product (last access: 4 July 2012), 2011.

Der Kiureghian, A. and Ditlevsen, O.: Aleatory or epistemic? Does it matter?, Special workshop on risk acceptance and risk communication, Stanford University, 2007.

DHI: MIKE FLOOD, available at: http://www.mikebydhi.com/ Products.aspx (last access: 4 July 2012), 2011.

Escuder-Bueno, I., Castillo-Rodríguez, J. T., Perales-Momparler, S., and Morales-Torres, A.: SUFRI Methodology for flood risk evaluation in urban areas, Decision guidance for decision maker, Report SUFRI project, WP3, CRUE-ERANET, Graz, Austria, 2011.

Estrela, T. and Quintas, L.: El modelo de flujo bidimensional GISPLANA, Revista de Obras Públicas, 104, 13-21, 1996.

ETH Zurich: BASEMENT - Basic Simulation Environment for computation of environmental flow and natural hazard simulation, Version 2.2, edited by: Faeh, R., Mueller, R., Rousselot, P., Vetsch, D., Volz, C., Vonwiller, L., Veprek, R. and Farshi, D., ETH Zurich, 2006-2011.

European Parliament: Directive 2007/60/EC on the assessment and management of flood risks, Official Journal of the European Union, October 2009.

Finaud-Guyon, P., Delenne, C., Guinot, C., and Llovel, C.: 1D-2D coupling for river flow modelling, CR. Mecànique, 339, 226234, 2011.

Gracia, A., Godé, L., Crego, E., Arrabal, M. A., Guirado, V., García, G., Lobera, C., González, S., and Martínez, E.: Riesgos y cuantificación de daños por inundación, $5^{\circ}$ Congreso Internacional de Ordenación del Territorio sobre Gestión Compartida de Recursos Hídricos Internacionales, Lisboa, 2010.

Gregory, M., Walker, B., Yi, S., Cunningham, B., and Kjelds, J.: Case studies in automated floodplain mapping, Proceedings of flood management ASCE conference, American Society of Civil Engineers, Reston, USA, 2007.

Halcrow: ISIS 2D software, available at: http://www.halcrow.com/ isis/isis2d.asp (last access: 4 July 2012), 2011.

Harr, M. E.: Reliability-based design in civil engineering, John Wiley and Sons, New York, USA, 1987.

He, H., Yu, Q., Zhou, J., Tian, Y. Q., and Chen, R. F.: Modelling complex flood flow evolution in the middle yellow river basin China, J. Hydrol., 353, 76-92, 2008.

Helmio, T.: Unsteady 1D flow model of a river with partially vegetated floodplains application to the Rhine river, Environ. Modell. Softw., 20, 361-375, 2005.

Hoek, E.: Practical Rock Engineering, online course, available at: http://www.rocscience.com/education/hoeks_corner (last access: 4 July 2012), 2007.

Horrit, M. S.: A linearized approach to flow resistance uncertainty in a 2-D finite volume model of flood flow, J. Hydrol., 316, 1327, 2006. 
Horrit, M. S. and Bates, P. D.: Evaluation of 1D and 2D numerical models for predicting river flood inundation, J. Hydrol., 268, 8799, 2002.

Inclam-University of Zaragoza, Departamento de mecánica de fluidos, Guad 2D Flow Software, Manual de Usuario, V1.1., 2011.

Innovyze: Infoworks RS software, available at: http://www. innovyze.com/products.aspx (last access: 4 July 2012), 2011.

Johnson, P. A.: Uncertainty of Hydraulic Parameters, J. Hydraul. Eng.-ASCE, 122, 112-114, 1996.

Kelly, K. S. and Krzysztofowicz, R.: A bivariate meta-Gaussian density for use in hydrology, Stoch. Hydrol. Hydraul., 11, 1731, 1997.

Kuiry, S. N., Sen, D., and Bates, P. D.: Coupled 1D-Quasi-2D flood inundation model with unstructured grids, J. Hydraul. Eng.ASCE, 136, 493-506, 2010.

Kun-Yeun, H., Jong-Tae, L., and Jae-Hong, P.: Flood inundation analysis resulting from levee-break, J. Hydraul. Res., 36, 747$759,1998$.

Latorre, B., Burguete, J., Murillo, J., Brufau, P., García-Navarro, P., Petaccia, G., Calvo, B., and Savi, F.: Flood wave simulation with 1D-2D coupled models, Proc. CCWI, Taylor and Francis, London, CCWI, 2009.

Liu, D. S. and Matthies, H. G.: Uncertainty quantification with spectral approximations of a flood model, IOP Conf. Ser.: Mater. Sci. Eng., 10, 012208, doi:10.1088/1757-899X/10/1/012208, 2010.

Mason, D. C., Cobby, D. M., Horrit, M. S., and Bates, P. D.: Flood plain friction parameterisation in two-dimensional river flood models using vegetation heights derived from airborne scanning laser altimetry, Hydrol. Process., 17, 1711-1732, 2003.

Mays, L. W. and Tung, Y. K.: Hydrosystems engineering and management, McGraw-Hill, New York, 1992.

Murillo, J., García-Navarro, P., Burguete, J., and Brufau, P.: The influence of source terms on stability, accuracy and conservation in two-dimensional shallow flow simulation using triangular finite volumes, Int. J. Numer. Meth. Fluids, 54, 543-590, 2007.

Murillo, J., Rodríguez-Pallarés, M., Andrés-Urrutia, A., Brufau, P., and García-Navarro, P.: A mathematical model for numerical simulation of shallow water flow: Description and practical application of GUAD 2D, Proc. of the iEMSs 2008, Int. Env. Mod. Soft. Soc., 3, 1431-1438, 2008.

Olivera, F., Rodríguez, M., and Murillo, J.: Floodplain delineation of the Ranillas Meander in Zaragoza using GUAD-2D, Proc. World Env. Water Resour. Congress, American Society of Civil Engineers, Reston, USA, 2008.

Palisade Corporation: @RISK software, User's Manual, available at: http://www.palisade.com/support/manuals.asp (last access: 4 July 2012), 2005.

Pappenberger, F., Beven, K., Horrit, M., and Blazkova, S.: Uncertainty in the calibration of effective roughness parameters in HEC-RAS using inundation and downstream level observations, J. Hydrol., 302, 46-49, 2005.

Pappenberger, F., Frodsham, K., Beven, K., Romanowicz, R., and Matgen, P.: Fuzzy set approach to calibrating distributed flood inundation models using remote sensing observations, Hydrol. Earth Syst. Sci., 11, 739-752, doi:10.5194/hess-11-739-2007, 2007.

Remo, J. W. F., Pinter, N., and Heine, R.: The use of retro and scenario modelling to assess effects of $100+$ years river of engineering and land cover change on middle and lower Mississipi flood stages, J. Hydrol., 269, 79-88, 2009.

Romanowicz, R. and Beven, K.: Dynamic real-time prediction of flood inundation probabilities, Hydrolog. Sci. J., 43, 181-196, 1998.

Rosenblueth, E.: Two-point estimates in probabilities, Appl. Math. Model., 5, 329-335, 1981.

Rubinstein, R. Y.: Simulation and the Monte Carlo Method, John Wiley \& Sons, 1981.

Sanders, B. F.: Evaluation of on line DEMs for flood inundation modelling, Adv. Water Resour., 20, 1831-1843, 2007.

Sarino and Serrano, S. E.: Development of the instantaneous unit hydrograph using stochastic differential equations, Stoch. Hydrol. Hydraul., 4, 151-160, 1990.

Shatnawu, F. M. and Goodall, J. L.: Comparison of flood top width predictions using surveyed and lidar derived channel geometries, J. Hydrol. Eng., 15, 97-106, 2010.

Shrestha, D. L. and Solomatine, D. P.: Data-driven approaches for estimating uncertainty in rainfall runoff modelling, Int. J. River Basin Manage., 6, 109-122, 2008.

UNWWAP - United Nations World Water Assessment Programme: Global trends in water-related disasters, an insight for policymakers, United Nations, 2009.

USACE: Hydraulic Engineering Center, Accuracy of computed water surface profiles, Technical report, Hydraulic Engineering Center, Davis, Calif., 1986.

USACE: HEC-RAS River Analysis System User's Manual, available at: http://www.hec.usace.army.mil (last access: 4 July 2012), 2002.

USACE: HEC-FDA Flood Damage Reduction Analysis User's Manual, available at: http://www.hec.usace.army.mil/software/ hec-fda/documentation/CPD-72_V1.2.4.pdf (last access: 4 July 2012), 2008.

Vallés-Morán, F. J., Escuder-Bueno, I., Andrés-Doménech, I., and Benavent-Gascón, C.: Modelos hidráulicos para la evaluación de estructuras fluviales de protección: cola del embalse de Arenós, Castellón, in: Risk Analysis, Dam Safety, Dam Security and Critical Infrastructure Management, edited by: Escuder-Bueno, I., Matheu, E., Altarejos-García, L., and Castillo-Rodríguez, J. T., Taylor and Francis, London, 2012.

Van der Knijff, J. M., Younis, J., and De Roo, A. P. J.: LISFLOOD: a GIS-based distributed model for river-basin scale water balance and flood simulation, Int. J. Geogr. Inf. Sci., 24, 189-212, 2010.

Wohl, E. E.: Uncertainty in flood estimates associated with roughness coefficient, J. Hydraul. Eng.-ASCE, 124, 219-223, 1998.

Wright, N. G., Villanueva, I., Bates, P. D., Mason, D. C., Wilson, M. D., Pender, G., and Neelz, S.: Case study of the use of remotely sensed data for modelling flood inundation on the river Severn, U.K., J. Hydrol. Eng., 134, 533-540, 2008.

Yeh, K. C. and Tung, Y. K.: Uncertainty and sensitivity analysis of pit-migration model, J. Hydraul. Eng.-ASCE, 119, 262-283, 1993.

Yoshida, H. and Dittrich, A.: 1D unsteady state flow simulation of a section of the upper Rhine, J. Hydrol., 269, 79-88, 2002.

Yue, S., Taha, B. M., Ouarda, J., Bobeé, B., Legendre, P., and Bruneau, P.: Approach for describing statistical properties of flood hydrograph, J. Hydrol. Eng., 7, 147-153, 2002. 